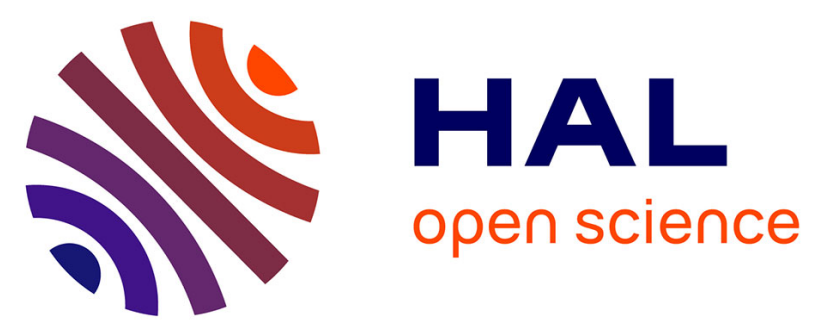

\title{
Ages and chemistry of mare basaltic units in the Grimaldi basin on the nearside of the Moon: Implications for the volcanic history of the basin
}

P.M. Thesniya, V. J. Rejesh, Jessica Flahaut

\section{- To cite this version:}

P.M. Thesniya, V. J. Rejesh, Jessica Flahaut. Ages and chemistry of mare basaltic units in the Grimaldi basin on the nearside of the Moon: Implications for the volcanic history of the basin. Meteoritics and Planetary Science, 2020, 55 (11), pp.2375-2403. 10.1111/maps.13579 . hal-03044708

\author{
HAL Id: hal-03044708 \\ https://hal.science/hal-03044708
}

Submitted on 7 Dec 2020

HAL is a multi-disciplinary open access archive for the deposit and dissemination of scientific research documents, whether they are published or not. The documents may come from teaching and research institutions in France or abroad, or from public or private research centers.
L'archive ouverte pluridisciplinaire $\mathbf{H A L}$, est destinée au dépôt et à la diffusion de documents scientifiques de niveau recherche, publiés ou non, émanant des établissements d'enseignement et de recherche français ou étrangers, des laboratoires publics ou privés. 


\title{
Ages and chemistry of mare basaltic units in the Grimaldi basin on the nearside of the Moon: Implications for the volcanic history of the basin
}

P. M. Thesniya ${ }^{1}$, V. J. Rajesh ${ }^{1, *}$, and J. Flahaut ${ }^{2}$

'Department of Earth and Space Sciences, Indian Institute of Space Science and Technology, Valiamala (P. O.), Thiruvananthapuram-695547, India

${ }^{2}$ Centre de Recherches Pétrographiques et Géochimiques (CRPG) - CNRS/ Université de Lorraine, 15 rue Notre Dame des Pauvres, 54500 Vandoeuvre les Nancy, FRANCE

Correspondence E-mail: rajeshvj@iist.ac.in

\begin{abstract}
Lunar mare basalts represent flood volcanism between $\sim 4.0$ and $1.2 \mathrm{Ga}$, therefore providing insights into the thermal and volcanic history of the Moon. The present study investigates the spectral and chemical characteristics as well as ages of the nearside mare basaltic units from the Grimaldi basin, namely Mare Grimaldi and Mare Riccioli, using a wealth of orbital remote sensing data. This study delineated distinct basaltic units of varying albedo, mineralogy, and titanium contents in both Mare Grimaldi and Mare Riccioli. The Crater sizefrequency Distribution technique revealed that at least two phases of basaltic magmatism have occurred in the Grimaldi basin spanning $~ 3.5 \mathrm{Ga}$ to $1.5 \mathrm{Ga}$ (Late Imbrian-Eratosthenian). HighTi olivine basalts dated at $2.05 \mathrm{Ga}$ are found to be surrounded by Late Imbrian $(\sim 3.47 \mathrm{Ga})$ low to intermediate- $\mathrm{Ti}$ basalts in Mare Grimaldi. Low to intermediate-Ti basalts observed in Mare Riccioli date back to two different volcanic events at $\sim 3.5 \mathrm{Ga}$ and $\sim 3.2$ billion years, while patches of basalts having remarkably higher titanium content within the Mare Riccioli record the youngest age of $\sim 1.5 \mathrm{Ga}$. The chemical trend of the pyroxenes from distinct basaltic units also revealed that multiple events of volcanism have occurred in the Grimaldi basin. The high-Ti basalts in the Mare Grimaldi crystallized from a Fe-enriched late-stage magma while the low-Ti basalts crystallized from an $\mathrm{Mg}$ and Ca-rich initial magma that experienced an ultra-late stage quenching. The low to intermediate-Ti basaltic magma erupted in both the units was derived by partial melting of early cumulate materials from the hybrid source region in the post-overturn upper mantle and made its way to the surface through dikes that propagated by excess pressures accumulated in the diapirs stalled at the base of the crust due to buoyancy trap. The intermediate to high-Ti magma erupted in the Mare Grimaldi was generated by a hot plume ascended from
\end{abstract}


deeper clinopyroxene-ilmenite rich cumulate layer near the core-mantle boundary. Whereas, the Eratosthenian ( 1.5 Ga) intermediate-Ti volcanic activity in the Mare Riccioli rather sourced from the ilmenite-clinopyroxene cumulate materials remained in the upper mantle after mantle overturn. The new results suggest that volcanism had not ceased in the Grimaldi basin at $3.27 \mathrm{Ga}$, rather it was active and fed by different mantle sources until $1.5 \mathrm{Ga}$ for a period spanning $\sim 2$ billion years.

Keywords: Mare Grimaldi, Mare Riccioli, pyroxene chemistry, crystallization history, mare volcanism, Moon.

\section{INTRODUCTION}

Earth's Moon is a natural laboratory for studying key planetary processes, including the formation and evolution of rocky planets. Scientific contributions from sample return missions and orbital measurements have greatly improved our understanding about the Moon. According to the Lunar Magma Ocean scenario, the Moon was melted up to a considerable depth following its accretion (Smith et al. 1970; Wood et al. 1970; Wood et al. 1972; Wood et al. 1975; Wood et al. 1983; Warren, 1985). As this magma ocean crystallized, denser mafic minerals (e.g., olivine) settled to the bottom and formed a part of the lunar mantle, whereas later formed plagioclase crystals floated upward and formed the anorthositic lunar crust (e.g., Warren, 1985; Shearer et al. 2006; Elardo et al. 2011; Charlier et al. 2018). Mare basalts are believed to have been formed by remelting of the lunar interior after this initial differentiation episode, through serial magmatism (e.g., Spudis and Davis 1986). They are emplaced as fissure-type eruptions of the low-viscosity basaltic magma through cracks and dikes and cover 17\% of the lunar surface area (Wilson and Head 1981; Head and Wilson 1992). The nature of source regions and causeand processes of remelting of the lunar interior for the generation of mare basaltic magmas are not yet well understood. The Surface dating of the mare basaltic units based on Crater Size-Frequency Distribution (CSFD) technique as well as radiometric ages of the returned lunar samples revealed that the mare volcanism on the Moon begun at around $\sim 3.9-4.0$ Ga ago and continued until $\sim 1.2 \mathrm{Ga}$, with a peak in the volcanic activity at $\sim 3.2-3.8 \mathrm{Ga}$ (Head and Wilson 1992; Hiesinger et al. 2000). In addition, the long time span of the eruption of the mare basalts along with vast diversity in their compositions across the lunar surface hint to the heterogeneous nature of lunar interior and make them potential candidates for understanding the variations in compositions, source regions, processes, and temperatures over time (Head and Wilson 1992; 
Giguere et al. 2000; Morota et al. 2011). Therefore, investigating the origin, diversity, and ages of mare basalts on the Moon is vital to understand its volcanic history and thermal evolution better.

The present study utilizes orbital remote sensing data from various lunar exploration missions to survey mare basalts of the Grimaldi basin on the western limb of the nearside Moon (Fig. 1). In the past few decades, the Visible Near-InfraRed (VNIR) orbital remote sensing technique emerged as a powerful tool to understand the surface mineralogy and chemical composition of the Moon. Pyroxene, plagioclase, and olivine minerals, which are major components of basalts, can be identified in the VNIR domain due to their diagnostic absorptions (see Methods section). Among these, pyroxene is a significant component in the basalts. The pyroxene group minerals form in all the stages of the crystallization of basaltic magma (Bence and Papike 1972; Shearer et al. 2006) and hence record the petrogenetic history of basalts (Bence and Papike 1972). Therefore, the chemical trend of pyroxenes in basalts should provide information about the crystallization history of basaltic magma. The chemistry of the pyroxenes present in the mare basalts and the relative abundances of endmember compositions can be determined based on their band parameter analysis, allowing us to retrieve information about the crystallization history of basaltic magma (e.g., Cloutis and Gaffey 1991a).

In the present study, mare basaltic units in the Grimaldi basin (Fig. 1) have been investigated using high-resolution optical and spectral imagery. $\mathrm{M}^{3}$ (Moon Mineralogy Mapper) data has been utilized for determining the mineralogy of mare basaltic units. Detailed chemistry of pyroxenes in the Mare Grimaldi and Mare Riccioli has been analyzed further based on the $\mathrm{M}^{3}$ absorption band characteristics. Moderate-high resolution spatial data from Terrain Mapping Camera (TMC), Terrain Camera (TMC), Lunar Reconnaissance Orbiter Camera (LROC), and topographic data from LOLA (Lunar Orbiter Laser Altimeter) have also been used to study the geological context and CSFD dating of the mare basaltic units in the Grimaldi basin. Based on the results, the origin, age, and emplacement mechanism of the basaltic units in the Mare Grimaldi and Mare Riccioli are discussed. The evolutionary stages of the Grimaldi basin involving the eruption of mare basalts in multiple stages and from diverse sources are also discussed.

\section{I.A. Geological background of the study area}

Grimaldi basin is a Pre-Nectarian two ringed, 'mascon' impact basin located at $5{ }^{\circ} \mathrm{S}, 68^{\circ} \mathrm{W}$ on the western limb of the nearside Moon, northeast of the Orientale basin (nearly 290 kilometers away) (Hartmann and Kuiper 1962; Wilhelms 1987) (Fig. 1A). The basin has a diameter of 440 $\mathrm{km}$ and an inner peak ring of $\sim 230 \mathrm{~km}$ in diameter, with an approximate depth estimated to 
2.7 km. (Fig. 1A, 1B) (C. A. Wood 2004). Lunar mascon (mass concentrations) basins such as the Grimaldi basin are characterized by positive free-air gravity anomalies in their central lowlying topography (Muller and Sjogren 1968; Melosh et al. 2013) which might be an indication of a positive density anomaly or excess distribution of mass within the crust or upper mantle (Freed et al. 2014; Zhong et al. 2018). Possibly, dense mare basaltic lavas and/ upliftment of the crustmantle interface would have contributed to the build-up of mass concentrations in basin depressions (Bratt et al. 1985; Melosh et al. 2013). Crustal thickness map derived from the GRAIL (Gravity Recovery and Interior Laboratory) data suggests a thickness of $\sim 7$ to $43 \mathrm{~km}$ for the crust beneath Grimaldi basin (Wieczorek et al. 2013), which is relatively thinner than the average lunar crust and make it, together with the occurrence of a mascon anomaly, a potential site of interest for this study.

Mare basalts (Mare Grimaldi, hereafter) of Eratosthenian age (termed as 'Elm' unit, Scott et al. 1977) fill part of the basin interior to the inner peak ring of $230 \mathrm{~km}$ diameter (Wilhelms 1987). The inner peak ring is prominent towards the SE and NW sides of the basin (Fig. 1C). The peak rings have been degraded partially and/ to some extent in the northeastern and south-western parts of the basin. The ringed peaks rise to an approximate height of $\sim 4.5 \mathrm{~km}$. The region that is lying between the inner ring and outer rim has been designated as the basin floor (Fig. 1B). On the west, this mascon basin is bounded by a regular border, having an average height of $1.21 \mathrm{~km}$, while on the opposite side, it is much broken. Riccioli crater is present on the north-western side of the basin. Mare basalts (Mare Riccioli, hereafter) have partially filled the floor of the Riccioli crater. In the south of the basin, the wall is broken by a large irregular depression. On the east, several grabens were identified (Fig. 2). At the extreme north end, several linear grabens cut through the wall and trend towards Lohrmann crater. Rimae Havelius is one such linear fracture trending in the NW-SE direction (Fig. 2). Wrinkle ridges were also found within Mare Grimaldi, trending in the NE-SW direction (Fig. 2). The Grimaldi region was initially mapped by McCauley et al. (1973), and later studied with NIR telescopic data by Peterson etal. (1995); various geological units in the Grimaldi region were delineated, and the composition and possible origin of these geological units and the stratigraphy of the pre-impact target site were also discussed. Spectral studies revealed that much of the Grimaldi region is covered by the outer facies of Havelius formation (Orientale Group) of noritic anorthosite and anorthositic norite in composition. The proximity of the Grimaldi basin to the Orientale basin $(\sim 3.8 \mathrm{Ga})$ (Yue et al. 2020) resulted in the blanketing of intact lithologies in the Grimaldi basin by the outer facies of the Orientale ejecta. The Orientale ejecta also overlies the interior of the Riccioli crater to the northwest of the crater. This blanketing of the Orientale ejecta is evident in long linear patterns on the surface of the Riccioli crater. Pure anorthosites were 
detected in the peak ring and represent the excavated anorthositic crust. The mare basalts within the Grimaldi have mafic assemblages dominated by High Calcium Pyroxenes (HCP) (Peterson et al. 1995). Gabbroic materials were also identified in excavated materials from beneath the Orientale related units at the location of three small impact craters (Fig. 2). Localized Dark Mantling Deposits (LDMD) of pyroclastic origin were also identified in the outer portion of the Grimaldi basin (McCauley 1973; Scott et al. 1977; Coombs 1988; Hawke et al. 1989a, b; Coombs and Hawke 1992). The compositional and morphological studies of Grimaldi LDMDs were carried out in detail by Gaddis et al. (2003) and Hawke et al. (2012). Elongated depressions aligned along NW-SE direction at the center of the Grimaldi deposit were suggested to be probable vents through which pyroclastic debris erupted. These vents have widths ranging from $\sim 3.1-3.2 \mathrm{~km}$, length from $4.4 \mathrm{~km}$ to $12.3 \mathrm{~km}$, and depths up to $1007 \mathrm{~m}$ (Hawke et al. 2012). The wt. \% FeO of the dark deposits show greater values ranging from 10-15 compared to that of the surrounding geological units ( 4-6 wt. \%) and wt. \% $\mathrm{TiO}_{2}$ values of $~ 3.6$ wt. \% (Hawke et al. 2012).

As discussed in the previous section, compositional studies of the Grimaldi basin were carried out by previous researchers. However, the mare basaltic units in the Grimaldi basin, Mare Grimaldi and Mare Riccioli have not been studied yet. The present study investigates those two mare basaltic units with newly available high-resolution datasets. The age of distinct basaltic units has been determined based on the CSFD technique. The mineralogical and spectral characteristics of these basaltic units have been examined. The chemistry of pyroxenes was also determined based on their band parameter analysis. Finally, the cooling and emplacement history of the basalts have been deciphered. The origin and emplacement of the younger high-Ti basalts within Mare Grimaldi and Mare Riccioli have also been discussed.

\section{DATASETS AND METHODS \\ II.A. Data}

Orbital remote sensing data from various lunar missions available in the public domain have been utilized in the present study. Hyperspectral data from Moon Mineralogy Mapper ( $\left.\mathrm{M}^{3}\right)$ on-board ISRO's Chandrayaan-I spacecraft have been used for the identification and mapping of minerals. $\mathrm{M}^{3}$ is a Visible Near-InfraRed (VNIR) hyperspectral imager aboard the Chandrayaan-1 mission, designed for compositional mapping of the lunar surface (Pieters et al. 2009; Klima et al. 2010; Green et al. 2011). The sensor has obtained global images of the Moon at a spatial resolution of $140 \mathrm{~m} /$ pixel in global mode and operated in the $446 \mathrm{~nm}-3000 \mathrm{~nm}$ wavelengths range with a spectral resolution of $20 \mathrm{~nm}-40 \mathrm{~nm}$. Fifteen orbits of Level 2 images from the optical period OP1B have been used in the present study, because of the OP1B complete coverage in the regions of interest (Boardman et al. 2011). Level 2 dataset, consisting of 
photometrically and thermally corrected reflectance data (Isaacson et al. 2011; Besse et al. 2013; Isaacson et al. 2013), were downloaded from the Lunar Orbiter Data Explorer Portal (http://ode.rsl.wustl.edu/moon/).

Moderate to-high spatial resolution optical imagery from Terrain Mapping Camera (TMC), Terrain Camera (TC), and NASA's Lunar Reconnaissance Orbiter Camera (LROC) have been used for the morphological studies.

TMC was a panchromatic stereo-viewing camera on-board Chandrayaan-1 with a spatial resolution of $5 \mathrm{~m}$, operating in the spectral range of 0.5-0.75 $\mu \mathrm{m}$ (Bhandari 2005; Kiran Kumar and Roy Chowdhury 2005a; Goswami and Annadurai 2009; Goswami 2010). TMC was aimed for topographic mapping of the Moon using high-resolution images acquired in the fore, nadir, and aft directions of the spacecraft movement (Gopala Krishna et al. 2009; Arya et al. 2011; Chauhan et al. 2012). TMC images were downloaded from the ISSDC (Indian Space Science Data Center) portal (https://webapps.issdc.gov.in). Full coverage of the mare was only available for Mare Riccioli.

The Kaguya TC is a push broom type stereoscopic imager that flew in the SELENE spacecraft (Haruyama et al. 2008). TC has a spatial resolution of 10m/pixel from the nominal 100 $\mathrm{km}$ SELENE orbit. TC operated in a panchromatic band ranging from $430-850 \mathrm{~nm}$. TC data were utilized in addition to TMC data because of its full coverage in the regions of Mare Grimaldi and Mare Riccioli. TC images were downloaded from the SELENE data archive portal (http://darts.isas.jaxa.jp/planet/pdap/selene/dataset). Mare Grimaldi units were dated using the mosaic generated from TC images, while TMC images were used for the Mare Riccioli.

Lunar Reconnaissance Orbiter Camera (LROC) is a set of high-resolution stereo-viewing cameras that flew on LRO (Lunar Reconnaissance Orbiter) mission of NASA (Tooley et al. 2010; Robinson et al. 2010; Speyerer et al. 2011; Scholten et al. 2012; Wagner et al. 2015). LROC-WAC (Wide-Angle Camera) images with a spatial resolution of $100 \mathrm{~m} /$ pixel have been used to understand the broad morphology and local geological setting of the study area. LROC WAC global mosaic of the Moon was downloaded from the Astrogeology Science Centre portal (https://astrogeology.usgs.gov.).

LOLA and Kaguya Terrain Camera (TC) merged DEM has been utilized in the present study to understand the topography of the study area. This DEM merge was generated at a horizontal resolution of 512 pixels/degree ( $\sim 59 \mathrm{~m}$ at the equator) with $\sim 3-4 \mathrm{~m}$ vertical accuracy (Barker et al. 2016a). LRO-LOLA and Kaguya TC merge global hillshade map has also been used in the present study. The data was downloaded from the Astrogeology Science Centre portal (https://astrogeology.usgs.gov.).

Olivine abundance maps of the region were generated using SELENE MI (Multiband Imager) data (Lemelin et al. 2016). The FeO abundance map generated from the SELENE MI data (Lemelin et 
al. 2016) and $\mathrm{TiO}_{2}$ abundance map generated from the LROC WAC (Wide Angle Camera) (Sato et al. 2017) was also utilized in the present study. These three abundance maps were obtained from the QuickMap web interface (https://quickmap.lroc.asu.edu).

\section{II.B. Methods}

\section{II.B.1. Mineralogical mapping}

$\mathrm{M}^{3}$ image strips were georeferenced and spatially subset to the boundary coordinates of the basin. The subset of images was then used to produce a reflectance mosaic of the Grimaldi basin. Albedo variations in the lithological units were observed based on the $\mathrm{M}^{3} \mathrm{R} 1578$ albedo map. The varying albedo in the $1578 \mathrm{~nm}$ band points towards the mineralogical differences in the region.

Lunar minerals and soils commonly exhibit absorption features at $1000 \mathrm{~nm}$ and $2000 \mathrm{~nm}$ (e.g., Pieters et al. 2009; Staid et al. 2011). Besides, space weathering effects tend to induce a positive (red) slope in the surface spectra and cause "optical maturation" (evidenced by a decrease in the average reflectance level and the absorption band strengths, e.g., Adams and McCord 1970; Pieters et al. 1993, 2000). Olivine can be identified by three overlapping broad absorption bands near $1 \mu \mathrm{m}(0.9 \mu \mathrm{m}, 1.05 \mu \mathrm{m}$, and $1.3 \mu \mathrm{m})$ and the absence of features at higher wavelengths (King and Ridley 1987; Burns 1970a; Burns 1970b; Burns et al. 1972; Burns 1973; Adams 1975; Burns 1993). Two major $\mathrm{Fe}_{2}+$ absorption bands from $0.9 \mu \mathrm{m}-1.05 \mu \mathrm{m}$ and $1.8 \mu \mathrm{m}-2.3 \mu \mathrm{m}$ in pyroxenes vary as a function of $\mathrm{Fe}^{2+}$ and $\mathrm{Ca}^{2+}$ content (Adams 1974). High Calcium Pyroxenes (HCP; e.g., augite, diopside) exhibit a $1 \mu \mathrm{m}$ absorption band centered between 0.91-1.06 $\mu \mathrm{m}$ with a $2 \mu \mathrm{m}$ band centered at 1.97-2.35 $\mu \mathrm{m}$. Low Calcium Pyroxenes (LCP; e.g., enstatite, hypersthene) also show both $1 \mu \mathrm{m}$ and $2 \mu \mathrm{m}$ absorption bands with band centres that vary from $0.90-0.93 \mu \mathrm{m}$ and 1.80 $2.10 \mu \mathrm{m}$ respectively (Burns 1970; Burns 1972; Adams 1974; Cloutis and Gaffey 1991a; Cloutis and Gaffey 1991b). In addition, the $1 \mu \mathrm{m}$ and $2 \mu \mathrm{m}$ band centres of LCP systematically shift to longer wavelengths with an increase in $\mathrm{Ca}^{2+}$ content (Adams 1974; Cloutis and Gaffey 1991b). This shift in the band centres to longer wavelengths as a function of $\mathrm{Ca}^{2+}$ content is owing to change in crystal field sites in which $\mathrm{Fe}^{2+}$ ions are located. (Burns 1970; Adams 1974). As a result, pigeonites, which are of intermediate Ca composition, show absorption bands near $0.93 \mu \mathrm{m}$ and $2 \mu \mathrm{m}$, sub-calcic augites have bands near $0.99 \mu \mathrm{m}$ and $2.18 \mu \mathrm{m}$, whereas absorption bands of the Ca-rich diopside are near $1.04 \mu \mathrm{m}$ and $2.3 \mu \mathrm{m}$ (Adams 1974). The band depths and positions of these absorption features can be used as a diagnostic parameter for discriminating the lunar lithologies. 
Integrated Band Depth (IBD) is a parameter used in the VIS-NIR spectroscopy for the spectral mapping of lunar mafic lithologies based on their ferrous absorption bands (e.g., Mustard et al. 2011; Besse et al. 2011; Isaacson et al. 2011; Staid et al. 2011). This parameter is sensitive to the abundances of pyroxenes, olivine, ilmenite, etc. in the surface lithologies. The Band Depth (BD) is the depth of an absorption band and is defined relative to the continuum (Clark and Roush 1984).

Band depth $=1$-continuum removed reflectance

$$
\begin{gathered}
\mathrm{IBD} 1000=\sum_{N=0}^{26} 1-R(789+20 n) / R c(789+20 n) \\
\mathrm{IBD} 2000=\sum_{N=0}^{21} 1-R(1658+40 n) / R c(1658+40 n)
\end{gathered}
$$

Where

$\mathrm{R}$

represents reflectance at a given wavelength, and Rc denotes reflectance relative to a local continuum defined between the inflection points on both sides of the absorption band.

IBD at $1000 \mathrm{~nm}$ and $2000 \mathrm{~nm}$ were generated to discriminate between mafic rich regions and anorthositic highland areas. IBD1000 parameter map has been generated by integrating the band depths between $789 \mathrm{~nm}$ and $1308 \mathrm{~nm}$ relative to the local continuum formed between $789 \mathrm{~nm}$ and $1308 \mathrm{~nm}$. The IBD1000 parameter is sensitive to the presence of both olivines and pyroxenes. IBD2000 parameter map has been generated by summing up the band depths between $1658 \mathrm{~nm}$ and $2498 \mathrm{~nm}$ relative to a local continuum drawn between $1658 \mathrm{~nm}$ and $2498 \mathrm{~nm}$ and is commonly used to map pyroxenes occurrences.

An $\mathrm{M}^{3}$ color composite image was generated using integrated band depth parameter maps. The IBD1000 parameter was assigned to the Red channel while Green and Blue channels were assigned the IBD2000 and R1578 bands, respectively. Reflectance spectra were collected from spectrally distinct regions using the color composite images generated for both the units. The soil spectra from each unit were extracted by averaging a number of pixels in that region. Apart from this, pyroxene-bearing spectra were also collected from smaller superposed craters within each unit. These spectra are obtained from single representative pixel in that location. The constituent mineral phases in the average soil spectra were identified based on their characteristic band parameters such as band center, relative band strengths, and the overall spectral pattern. The spectra are a convolution of multiple components present on the target surface. In the case of basaltsthe $1000 \mathrm{~nm}$ and $2000 \mathrm{~nm}$ absorption bands of pyroxene group minerals are the dominant features. The dominant pyroxene-related features will superimpose the effects of other 
mixed components such as plagioclase and /or olivine on the reflectance spectra. However, the presence of mixed phases may also impart a slope to the spectra and cause a shift in the 1000 $\mathrm{nm}$ and $2000 \mathrm{~nm}$ apparent band minima. The wavelength-dependent scattering would also cause a greater continuum slope to the spectra, and consequently, the dominant $1000 \mathrm{~nm}$ and $2000 \mathrm{~nm}$ absorption bands would have negligible band minima (Clark and Roush 1984). Therefore, continuum removal of the spectra has to be performed to reduce these effects of continuum slope on the major absorption bands before their band parameter analysis (Clark and Roush 1984). For the continuum removal, the local maxima on both sides of the absorption bands were determined for each analyzed spectrum. And a straight line tangent was drawn between the local maxima points to define the continuum slope. Continuum removal of the spectra has been done by dividing the spectra by the straight-line continuum drawn between inflection points on both sides of the absorptions for the Band I and Band II (Suppl Fig. 1). The Band Centre (BC), Band Area (BA) and Band Strength (BS) are calculated for each endmember spectra based on the method described in Cloutis et al. 1986 and Gaffey et al. 2002 which was later adopted and successfully applied by Kaur et al. (2013) and Chauhan et al. (2018) for estimating the chemical composition of pyroxenes within the mare basalts on the Moon. The Band Center (BC) is calculated as the band minima after removal of the continuum slope. A 3rd-4th order polynomial function was fitted to the bottom of the absorption features, and the band center is calculated as the minimum point of the fitted polynomial. The error associated with the BC calculation was determined through an iterative process by changing the number of points on either side of a visually determined band minimum five to six times, and band centers are calculated each time. The calculated band center values are averaged, and the average $\mathrm{BC}$ value is used for further analysis. Standard deviation (STD) was also determined using the estimated band center values. $\mathrm{BS}$ is the depth of the absorption feature relative to the continuum. BA is calculated as the area between the continuum line and the data points in the absorption band of the spectra. The Band Area Ratio (BAR) is the ratio of Band II area to Band I area of pyroxenes. Band I is sensitive to the relative abundances and composition of pyroxenes and /or olivine, while Band II is sensitive to the abundance of pyroxenes in the spectra (Cloutis et al. 1986). BAR is calculated to determine the relative abundances of olivine and pyroxenes in the mare basalt spectra. Increased BAR value suggests the higher abundance of pyroxenes in the spectra, and lower values indicate the presence of mixed olivine phase in the spectra (Cloutis et al. 1986; Gaffey et al. 1993). The effect of olivine in the spectra was removed by using the calibration given in Cloutis et al. (1986) and Gaffey et al. (2002). A correction factor was applied to the Band I center to remove the potential contribution of olivine from the spectra before determining the pyroxene composition. The correction factor was derived by calculating the displacement in the Band I center using BAR vs Band I center calibration. The calculated Band I displacement was later applied for olivine correction of Band I 
center. The estimated Band I center (olivine corrected) and Band II center values are applied for calculating the molar $\mathrm{Ca}, \mathrm{Fe}$ and $\mathrm{Mg}$ content in pyroxenes using a set of equations given by Gaffey et al. (2002).

$$
\begin{aligned}
& \mathrm{Wo}( \pm 3)=347.9 \times \mathrm{BI} \text { Center }(\mu \mathrm{m})-313.6 \\
& \text { (Fs }<10 ; \text { Wo } \sim 5-35 \text { excluded }) \\
& \mathrm{Wo}( \pm 3)=456.2 \times \mathrm{BI} \text { Center }(\mu \mathrm{m})-416.9 \\
& \left(\mathrm{Fs}=10-25 ; \mathrm{Wo}_{\sim 10-25} \text { excluded }\right) \\
& \mathrm{Wo}( \pm 4)=418.9 \times \mathrm{BI} \text { Center }(\mu \mathrm{m})-380.9 \\
& (\mathrm{Fs}=25-50) \\
& \operatorname{Fs}( \pm 5)=268.2 \times \text { BII Center }(\mu \mathrm{m})-483.7 \\
& \left(\mathrm{Wo}_{\mathrm{O}}<11\right) \\
& \mathrm{Fs}( \pm 5)=57.5 \times \text { BII Center }(\mu \mathrm{m})-72.7 \\
& \left(\mathrm{Wo}_{\mathrm{O}}=11-30, \mathrm{Fs}_{<25} \text { excluded }\right) \\
& \operatorname{Fs}( \pm 4)=-12.9 \times \text { BII Center }(\mu \mathrm{m})+45.9 \\
& (\mathrm{Wo}=30-45) \\
& \operatorname{Fs}( \pm 4)=-118.0 \times \operatorname{BIICenter}(\mu \mathrm{m})+278.5 \\
& \text { (Wo }>45)
\end{aligned}
$$

The estimated molar contents of endmember pyroxene compositions are projected on to a pyroxene quadrilateral plot to understand the relative abundances of endmember compositions. The crystallization trend of basaltic magma was determined based on the pyroxene compositional trend observed in the quadrilateral plot (Lindsley and Anderson 1983).

\section{II.B.2. Datation with CSFD technique}

CSFD technique has been adopted for determining the absolute model ages of the distinct basaltic units within Mare Grimaldi and Mare Riccioli. The CSFD method is a widely used technique to estimate the absolute and relative ages of the photogeological units on planetary surfaces (Neukum et al. 1983; Neukum and Ivanov 1994; Hiesinger et al. 2000; Neukum et al. 2001). The method primarily involves measurement of the surface area of the target unit as well as the diameter of each primary crater within the unit. The obtained crater diameters were plotted as cumulative distribution in Craterstats 2 software. Craters with diameters between 200 
$\mathrm{m}$ to $2 \mathrm{~km}$ have been considered for age estimation. The age is estimated by fitting the lunar production function to the cumulative crater distribution (Neukum et al. 1975; Neukum 1983; Neukum and Ivanov 1994).

\section{RESULTS}

Mare Grimaldi and Mare Riccioli were previously mapped as two basaltic units emplaced during the Imbrian-Eratosthenian period ( 3.25-3.48 Ga), consisting of low albedo units with superposed rays and Eratosthenian craters (Fig. 3; Wilhelms et al. 1987). Albedo variations and mineralogy is a widely used method for defining distinct geological units (e.g., Staid et al. 2011; Staid and Besse 2013; Kaur et al. 2013; Zhang et al. 2014). In the present study, the $\mathrm{M}^{3} \mathrm{R} 1578$ albedo map has been used to understand the albedo variations in the Mare Grimaldi and Mare Riccioli basaltic units while the $\mathrm{M}^{3} \mathrm{RGB}$ composite highlight variations in mineralogy (Fig. 3). Fresh impact craters which are found to have excavated these basaltic units exhibit spectral signatures of pyroxene group minerals. The albedo variations, chemical composition and mineralogy, $\mathrm{FeO}$ and $\mathrm{TiO}_{2}$ abundances, pyroxene crystallization trend, model ages, and emplacement history of Mare Grimaldi and Mare Riccioli are discussed separately in the following sections.

\section{III.A. Spectral and compositional diversity of the Mare Grimaldi and Mare Riccioli units}

\section{III.A.1. Unit mapping from $M^{3}$ albedo variations}

Mare Grimaldi has occupied the low-lying regions of the basin interior. Within the Mare Grimaldi, notable variations in the R1578 albedo can be observed (Fig. 3A). Albedo variations result from the mafic mineral abundances as well as optical maturity of the surface. $\mathrm{M}^{3} \mathrm{R} 1578$ albedo in the Mare Grimaldi ranges from $\sim 0.01-0.12$ (Fig. 3A). The measured albedo is less compared to the bright surrounding highlands $(>0.09)$ in the Grimaldi basin, due to the presence of mare basalts containing mafic minerals. The bright ejecta rays from the Grimaldi B crater located in the NNW of the Mare Grimaldi are seen to have partially blanketed the top layer of the mare basalt (Fig. 3A). The prominent albedo variations in the Mare Grimaldi is attributed to the distribution of ejecta rays from the Grimaldi B crater. The basaltic units towards the northern half of the Mare Grimaldi show higher reflectance because of its proximity to the Grimaldi B crater. The relatively younger superposed craters, which appear to have excavated the basaltic units in the Mare Grimaldi, also display relatively higher albedo values (0.07-0.12). Based on the prominent variations in the albedo, distinct basaltic units have been delineated within the Mare Grimaldi. Four major basaltic units have been defined, namely, G1, G2, G3, and 
G4 (Fig. 3A). These units are labelled in the order of increasing albedo. The G1 unit, located in the SW part of the Mare Grimaldi, displays the lowest albedo values ( 0.04) (Fig. 3A). The G1 unit is surrounded by the $\mathrm{G} 2$ unit having albedo values in the $\sim 0.05-0.06$ range. The albedo in the G3 unit ranges from 0.06-0.07. G4 unit exhibits the highest albedo in the Mare Grimaldi ranging from $~ 0.08-0.09$. However, the smaller craters within the Mare Grimaldi exhibits a longer range of albedo from 0.01-0.12. The lower albedo in these craters, ranging between 0.01-0.04, is a manifestation of the mafic mineral exposures on the crater wall while the higher values ( 0.1) indicate less optical maturity of the crater. Mare Riccioli basalts exhibit a slightly varying albedo ranging from $\sim 0.02-0.10$ (Fig. 3B). The low-albedo regions ( 0.04-0.05) are confined to the central portion of the Mare Riccioli as well as the inner walls of superposed craters. The surrounding regions show albedo values between 0.06-0.11. The intermediate to $\mathrm{lw}$ albedo regions in the central portion of the Mare Riccioli is designated as R1 unit. Within the R1 unit, few patches of distinctively lower albedo can also be seen towards the northern central region (Fig. 3B). These small patches of low albedo regions (0.02) might be attributed to a varying maturity of the surface units and /or later younger eruptions. The surrounding higher albedo region is labeled as R2 unit (Fig. 3B). The Mare Grimaldi units have slightly lower albedo values compared to the Riccioli basalts, possibly due to the more mafic-rich composition of the Mare Grimaldi basalts.

\section{III.A.2. $\mathrm{FeO}$ and $\mathrm{TiO}_{2}$ abundance map}

Kaguya-derived $\mathrm{FeO}$ and $\mathrm{TiO}_{2}$ abundances of the Mare Grimaldi and Mare Riccioli have also been used to understand the chemical nature of these basaltic units (Fig. 4). In the Mare Grimaldi, the G1 unit shows higher $\mathrm{FeO}\left(>22.5\right.$ wt. \%) and $\mathrm{TiO}_{2}(>9$ wt. \%) contents, indicating the presence of high-Ti basalts in the region (Fig. 4A-B). The $\mathrm{G} 2$ unit shows $\mathrm{FeO}$ and $\mathrm{TiO}_{2}$ contents between 20-22.5 wt. \% and 6-10 wt. \% respectively. The G3 unit exhibits relatively higher FeO abundance values (15-20 wt. \%) than G4 unit and intermediate $\mathrm{TiO}_{2}$ contents ranging from 4-9 wt. $\%$. The outer unit, G4 towards the northern part of the Mare Grimaldi, displays medium FeO contents (12.5-15 wt. \%) and low to intermediate $\mathrm{TiO}_{2}$ abundance values (2-5 wt. \%). The varying $\mathrm{FeO}$ and $\mathrm{TiO}_{2}$ contents are consistent with the spectrally defined distinct basaltic units in the Mare Grimaldi. The intermediate to high-Ti basalts (G1 and G2 units) are seen to be surrounded by the low to intermediate-Ti basalts comprising the G2, G3, and G4 units (Fig. 4B). The G1 unit having the lowest albedo possess higher $\mathrm{FeO}$ and $\mathrm{TiO}_{2}$ abundance values. The boundary of the G1 unit is delineated based on the distinctly visible extents of the high $\mathrm{TiO}_{2}$ and $\mathrm{FeO}$ contents (Fig. 4A-B). It is apparent that the high $\mathrm{TiO}_{2}$ regions have a greater spatial extent and are seen as intermixed with the intermediate-Ti unit that overlies one another in the G1 and G2 units. The 
lower albedo values in the spectrally defined units are linked with the higher $\mathrm{TiO}_{2}$ and $\mathrm{FeO}$ abundance in those units. The mafic-rich composition (higher $\mathrm{FeO}$ and $\mathrm{TiO}_{2}$ ) of these units causes the observed decrease in their albedo.

In the Mare Riccioli, the FeO content ranges from 12.5-22.5 wt. \% and $\mathrm{TiO}_{2}$ contents between 28 wt. $\%$ (Fig. 4C-D). The R1 unit exhibits higher FeO (20-22.5 wt. \%) and low to intermediate $\mathrm{TiO}_{2}$ (3-8 wt. \%) abundance values while the $\mathrm{R} 2$ unit shows relatively lower $\mathrm{FeO}$ (12.5-20 wt. \%) and low to intermediate $\mathrm{TiO}_{2}(2-5$ wt. \%) abundance values. The $\mathrm{R} 1$ unit is surrounded by the R2 unit of relatively low- $\mathrm{TiO}_{2}$ contents to the northwest. Small patches of higher $\mathrm{FeO}$ and $\mathrm{TiO}_{2}$ concentrations are seen within the $\mathrm{R} 1$ unit towards the northern part (Fig. 4C-D). The intermediate-low albedo unit (R1) defined in Fig. 3B does not display a uniform distribution of $\mathrm{FeO}$ and $\mathrm{TiO}_{2}$ contents in the abundance map (Fig. 4C-D). The unit rather shows an uneven distribution of $\mathrm{FeO}$ and $\mathrm{TiO}_{2}$ abundances.

\section{III.A.3. Compositional variations from color composite images}

$\mathrm{M}^{3}$ color composite images generated by assigning IBD1000, IBD2000, and R1578 to the red, green, and blue channels, respectively, are shown in Fig. 5. In the color composite image, the basaltic units are displayed in the shades of yellow-orange. The varying color shades in the image are attributed to the differences in ferrous band strengths as well as band centers arising from the variations in the mineralogy and /or optical maturity (Staid et al. 2011; Cheek et al. 2011). Distinct basaltic units within Mare Grimaldi and Mare Riccioli were distinguished based on the color differences in the color composite image. The approximate boundary of the G1 unit was delineated based on the spectrally visible spatial extent of $\mathrm{TiO}_{2}$ abundance in the unit, as the spectral contrast between G1 and surrounding G2 unit is not very obvious in the color composite image (Fig. 5A). The yellow, green, and orange shades represent compositional variations as well as the maturity of the mafic lithologies (Cheek et al. 2011). In the Mare Grimaldi, the G1 and G2 unit exhibits slightly brown-red hues (Fig. 5A). The surrounding low-Ti basaltic units, G3, and G4 exhibit yellow-blue shades. The smaller craters within the Mare Grimaldi shows brighter yellow tones representing the pyroxene-rich materials of underlying basaltic units exposed on these crater walls (Staid et al. 2011) (Fig. 5A). The surrounding highlands are displayed in the blue shades resulting from the high feldspathic contents and /or greater maturity of the highland soi(Cheek et al. 2011). Similarly, in the color composite image of the Mare Riccioli, the basaltic units are displayed in the yellow-orange shades (Fig. 5B). The R1 unit exhibits yellow shades consistent with the low to intermediate-Ti contents in the unit. The relatively low-Ti basalts, R2 unit is displayed in the light green-orange shades. The smaller craters having pyroxene-rich materials are shown in the bright yellow shades (Fig. 5B). 
The brown to red-hued basaltic units (G1 and G2) in the Mare Grimaldi also exhibit high$\mathrm{FeO}$ and high- $\mathrm{TiO}_{2}$ contents, as shown in Fig. 4A-B. The late-stage high-Ti basalts would have a unique color, composition, and spectral characteristics, and they often represent the younger volcanic materials (Staid et al. 2011). In the Clementine color ratio image, the late-stage high-Ti basalts in the G1 and G2 units appear blue because of higher spectral reflectance in the blue region of the electromagnetic spectrum (e.g., McEwen et al. 1994; Pieters et al. 1998) (Fig. 5C). In the $\mathrm{M}^{3}$ color composite image, the high-Ti basalts in the central portion towards the southern half of the Mare Grimaldi display brown-red hues and are, therefore, thought to represent late-stage younger basalts (Fig. 5A).

The brown-red hues of the high-Ti basalts of the Mare Grimaldi in the $\mathrm{M}^{3}$ color composite are likely caused by the increased band strengths in the $1000 \mathrm{~nm}$ region relative to a weaker $2000 \mathrm{~nm}$ absorption band and might indicate the presence of olivine (Staid et al. 2011; Zhang et al. 2016) (Fig. 6A). The strong and broad absorption feature in the region of $1000 \mathrm{~nm}$ might also reflect the presence of FeO-rich glass in basalts (Pieters et al. 1980). In the Mare Grimaldi, the brown-red-hues are likely to be caused by a higher abundance of olivine. IBD $1000 \mathrm{~nm}$ parameter map has been used to estimate the olivine abundance in the Mare Grimaldi. The IBD1000 parameter is sensitive to the strengths of absorption features in the $1000 \mathrm{~nm}$ region of the spectra. Olivine has the diagnostic absorption band only in the $1000 \mathrm{~nm}$ region, unlike pyroxenes which have two major diagnostic bands both in the $1000 \mathrm{~nm}$ and 2000 $\mathrm{nm}$ regions. Therefore, the abundance of olivine in the basalts can be mapped based on the IBD1000 nm parameter. In the IBD1000 map, the central portion towards the southern half of the Mare Grimaldi exhibit higher abundance values (white and purple hues) (Fig. 6A). The higher values in this parameter map are consistent with the high Fe-Ti region of the Mare Grimaldi (G1 and G2) (Fig. 6A). This higher olivine abundance associated with the high-Ti basalts in the Mare Grimaldi is validated by the Kaguya MI-derived olivine abundance map (Fig. 6C). The MI olivine abundance map displays greater abundance values in the G1 (0.17-0.22 wt. \%) and G2 (0.10.2 wt. \%) units of the Mare Grimaldi (Fig. 6C). The low to intermediate-Ti basalts in the Mare Riccioli also show a higher IBD1000 value (Fig. 6B). However, the Riccioli units are not showing higher values (0.025-0.15 wt. \%) in the MI olivine abundance map, which is contrary to the higher IBD1000 value (Fig. 6D). This discrepancy in the olivine abundance of Mare Riccioli units would have been caused by the contribution of other mixed phases to the $1000 \mathrm{~nm}$ band strengths that resulted in the increased band strength values in the $1000 \mathrm{~nm}$ region and thereby higher abundance values in the IBD III.A.4. Mineralogical signatures from $M^{3}$ spectra 
Exposure of lunar surface to space weathering reduces the overall reflectance, and spectral contrast weakens the absorption features of different chemical phases and increases the soil maturity (e.g., Staid and Pieters 2000). In the Grimaldi basin, materials of highly immature (e.g., the interior of the superposed craters), as well as mature soils, are distributed unevenly. Several soil spectra were obtained from individual basaltic units for understanding the spectral characteristics and identifying the mineralogy. Reflectance spectra of mare soils were obtained from mature locations while pyroxene-bearing spectra were obtained from immature regions in the interior of the superposed craters. These variations in the optical maturity of the mare units caused by the space-weathering effects are determined based on the relation of $\mathrm{R} 950 / \mathrm{R} 750$ (ratio of the reflectances at $950 \mathrm{~nm}$ and $750 \mathrm{~nm}$ ) vs $750 \mathrm{~nm}$ reflectance (R750). The reflectance at $750 \mathrm{~nm}$ indicates the variations in soil compositions and maturity. While, the R950/R750 ratio is linked to the mafic absorption band strength, which is sensitive to the optical maturity of the mare and highland soils (e.g., Wohler et al., 2006). Therefore, the linear relationship between $750 \mathrm{~nm}$ albedo and reflectance ratio on the ratio-reflectance plot allows us to distinguish the soil materials and the trends related to soil maturity can be evaluated (Lucey et al., 1995; 1998; 2000). On the ratio-reflectance plot, the pixels occupying low-ratio, brighter end belong to immature materials while high-ratio, dark end represents mature soils (Lucey et al., 1998; Staid and Pieters 2000). Relatively younger superposed craters within the Mare Grimaldi and Mare Riccioli expose materials of underlying basaltic units from depth. These smaller craters that appear to have excavated the basaltic units are subjected to space weathering effects for relatively less time and remain fresh or immature. Similar mature and immature regions have been distinguished based on the relation of R950/R750 vs R750. Representative soil spectra were extracted from each unit by averaging the reflectance of these immature pixels (Fig. 7, 8, \& 9). Reflectance spectra from the surrounding highland soils are also shown for comparison (Fig. 7A-B). The locations from where the spectra have been obtained are marked as white polygons in Fig. 5A-B. Crystalline plagioclase exposures and pure anorthosite bearing spectra were identified from the wall of the Grimaldi S crater (Fig. 7E-F). This anorthosite exposure may represent primary crustal material from the PAN (Pure Anorthosite) layer (Ohtake et al. 2009; Donnaldson-Hanna et al. 2014). The soil spectra collected from the distinct basaltic units exhibit varying spectral slope and absorption characteristics. The soil spectra from the G1 unit display lower average albedo values and a relatively stronger absorption band in the $1000 \mathrm{~nm}$ region (Fig. 7A-B). A weaker absorption band has been observed in the $2000 \mathrm{~nm}$ region. Moreover, the band I absorption is observed to be shifted longward in response to the $\mathrm{Fe}^{2+}$ electronic transition absorption. The band strength in the $1000 \mathrm{~nm}$ region is higher relative to the $2000 \mathrm{~nm}$ band. The presence of olivine would increase the strength of the $1000 \mathrm{~nm}$ band relative to the Band II absorption and bring a longward shift in the Band I absorption. The presence of FeO-rich glass might also contribute to the longward shift 
of Band I center (Besse et al. 2014). However, the presence of glass will additionally contribute to a shortward shift in Band II center and higher Band II strength relative to Band I, which is contrary to the G1 spectra. Therefore, the observed longward shift in Band I and greater band I strength is conclusively consistent with the olivine abundance in the G1 unit of Mare Grimaldi. This evidence favors the occurrence of olivine basalt in the Mare Grimaldi (Fig. 6). The soil spectra from the G2 unit exhibit relatively symmetric Band I and Band II absorptions (Fig. 7A-B). The Band I appear to be narrower compared to a broader Band II absorption. The spectra from the G2 unit is dominated by pyroxene-rich materials. The G3 unit soil spectra exhibit evident absorption features in the $1000 \mathrm{~nm}$ and $2000 \mathrm{~nm}$ regions (Fig. 7A-B). However, the Band II absorption is broader relative to a narrow Band I absorptions. The average soil spectra from the G4 unit also exhibits absorptions in the $1000 \mathrm{~nm}$ and $2000 \mathrm{~nm}$ regions with a relatively stronger and broader Band II absorption (Fig. 7A-B). The soil spectra from the R1 unit in the Mare Riccioli have spectral characteristics more or less similar to the G1 unit of Mare Grimaldi (Fig. 7C-D). The BanI absorption is relatively stronger and shifted slightly longward. The R2 spectra also show both the Band I and Band II absorptions with a stronger and broader absorption band in the $2000 \mathrm{~nm}$ region (Fig. 7C-D). The $\mathrm{R} 2$ unit is dominated by pyroxenerich materials.

The pyroxene-bearing spectra obtained from the inner walls of superposed craters in Mare Grimaldi and Mare Riccioli were identified and found that the clinopyroxenes are the major component present in the spectra (Fig. 8 \& 9). As discussed earlier, clinopyroxenes exhibit two major absorption bands at $1000 \mathrm{~nm}$ (Band I) and $2000 \mathrm{~nm}$ (Band II) in response to the electronic transition absorptions by $\mathrm{Fe}^{2+}$ ions in the M1 and M2 sites. The clinopyroxene-rich spectra in the G1, G2, and G3 unit exhibit stronger Band I absorption relative to the Band II absorption, suggesting the presence of mixed phases in the spectra (Fig. 8A-F). However, the clinopyroxenerich spectra from the G4 unit, as well as Riccioli units exhibit more or less symmetrical and stronger Band I and Band II absorptions, which indicate that clinopyroxene is dominating the reflectance spectra from these regions (Fig. 8G-H). The pyroxene spectra from the R1 and R2 units are also showing symmetrical Band I and Band II absorption bands (Fig. 9A-D).

\section{III.A.5. Determining the composition of the pyroxenes based on their band parameter analysis}

The 'Elm' basaltic units in the Mare Riccioli and Mare Grimaldi are dominated by clinopyroxenes. The Band I and Band II absorption features of the pyroxenes would enable us to retrieve relevant information about their chemistry as well as crystallization conditions (Bence and Papike 1972). Hence, the Band I and Band II parameters such as BC, BS, and BA have been calculated for the collected spectra based on the method described in the methodology 
section. The Mare Grimaldi units show Band I centres between $~ 985$ nm-991 nm while the Band II centres between $2142 \mathrm{~nm}-2159 \mathrm{~nm}$. On the other hand, the Mare Riccioli units show both the Band I and Band II centers at relatively shorter wavelengths ( 969-983 nm, 2074-2136 nm). The variations in the band centers are consistent with the $\mathrm{TiO}_{2}$ and $\mathrm{FeO}$ contents of different units. The Band I and Band II centres are found to have shifted to somewhat longer wavelengths with the enhanced $\mathrm{TiO}_{2}$ abundances of the basaltic units.

BAR vs. B I center is plotted to understand the mixing of olivine and pyroxenes in the obtained spectra as the olivine abundance is noticeably higher in the high-Ti units (after Gaffey et al. 1993) (Fig. 10A). The Mare Grimaldi and Mare Riccioli compositions are falling in the region of clinopyroxenes and orthopyroxenes $(\mathrm{Opx}>\mathrm{Ol})$ in the BAR vs. Band I center plot. The BAR for the Mare Grimaldi compositions (fresh craters as well as soil samples) is between 0.4-2 (Fig. 10A). The Band I center ranges from $\sim 963 \mathrm{~nm}-1032 \mathrm{~nm}$. The Mare Riccioli compositions have BAR in the 0.6-1.7 range, while the Band I center ranges from $\sim 951 \mathrm{~nm}-1016 \mathrm{~nm}$ (Fig. 10A). The BAR increases as the pyroxene component dominate the reflectance spectra (Cloutis et al. 1986). Mare Riccioli compositions have BAR values greater than the Mare Grimaldi compositions, suggesting the elative dominance of pyroxenes in the Mare Riccioli compositions (Fig. 10A). The Band I center shifts longward with the corresponding decrease in the BAR when the olivine content in the spectra increases (Cloutis et al. 1986). The soil sample from the Mare Grimaldi and Mare Riccioli showing lower BAR values and longer Band I centers indicate the mixed olivine content in the spectra. This mixed olivine content yet again validates the observed higher olivine abundance of the high-Ti basaltic units in the Mare Grimaldi. As most of the soil samples show evidence of mixed olivine component, these soil compositions are not included in the further band parameter analysis. Since the mixing of olivine and pyroxene phase in the reflectance spectra is noticed, the displacement in the Band I center of pyroxenes has to be corrected to remove the spectral effects of olivine (see Methods section). The estimated displacement in the Band I center is approximately $23 \mathrm{~nm}$ on average (Fig. 10B). The estimated Band I (corrected) and Band II parameters for the pyroxenes from each basaltic unit are given in Table 1. The corrected Band I centers and Band II centers have been used for the Band II vs. Band I plot. This Band II vs. Band I plot is used to understand the compositional variations among the pyroxenes (Fig. 10C). The reference data from Adams (1974), later modified by Cloutis and Gaffey (1991a) and synthetic pyroxene data from Klima et al. (2011) are also plotted for comparison (Fig. 10C). The Mare Grimaldi and Mare Riccioli pyroxene compositions are falling along with the main trend of the reference pyroxene data. The corrected Band I center of the Mare Grimaldi pyroxenes range from 937 nm - 983 nm, while the Band II center ranges between 2097 nm - 2199 nm (with average values of $959 \mathrm{~nm}$ and $2148 \mathrm{~nm}$ ). Mare Riccioli pyroxene compositions exhibit Band I center 
between $951 \mathrm{~nm}-1004 \mathrm{~nm}$ and Band II center in the $1997 \mathrm{~nm}-2180 \mathrm{~nm}$ range (with average values of $976 \mathrm{~nm}$ and $2108 \mathrm{~nm}$ ). The systematic shift of Band II center to longer wavelengths is owing to the increase in the $\mathrm{Ca}^{2+}$ content (Cloutis and Gaffey 1991a; Klima et al. 2011). The band center values indicate that the pyroxene compositions are mainly pigeonite and augite in the Mare Grimaldi and Mare Riccioli (Fig. 10C).

The estimated band parameters of pyroxenes can also be used to calculate the relative abundance of endmember pyroxene compositions (Gaffey et al. 2002; Kaur et al. 2013; Chauhan et al. 2018). The abundance of these pyroxenes is determined using the calibration equations described in the methodology section (Gaffey et al. 2002). The estimated pyroxene abundances have been projected onto a pyroxene quadrilateral plot (Suppl Fig. 2) to understand the relative proportions of $\mathrm{Ca}, \mathrm{Mg}$, and $\mathrm{Fe}$ (Lindsley and Anderson 1983). In the quadrilateral, the major pyroxene compositions in Mare Grimaldi and Mare Riccioli are pigeonite and augite (Suppl Fig. 2). However, most of the pyroxene compositions in the Mare Grimaldi and Mare Riccioli are falling in the 'forbidden zone' of the pyroxene quadrilateral (Fig. 10D). In the forbidden region, single pyroxene of intermediate composition is unstable at low pressures (Lindsley and Anderson 1983). However, Fe-rich pyroxene compositions, often zoned to pyroxferroite, falling in the forbidden region, were also observed in lunar basalts as a result of metastability and rapid crystallization (cf. Papike et al. 1976; Papike and Vaniman 1978). Typically, mare basalts contain a stable equilibrium three-phase assemblage of $\mathrm{CaFe}$ pyroxene-Fe olivine-silica that formed through crystallization from a Fe-enriched latestage melt (cf. Papike et al. 1991). In some cases, extremely Fe-rich pyroxene or a silicate mineral called pyroxferroite $\left(\sim \mathrm{Wo}_{14} \mathrm{En}_{11} \mathrm{Fs}_{75}\right)$ crystallizes metastably relative to the typical pyroxeneolivine-silica assemblage due to rapid cooling of the late-stage melts. These metastable iron-rich pyroxenes occupy the "forbidden region" near the Hd-Fe join of the "pyroxene quadrilateral' (Lindsley and Anderson 1983). Similar compositions formed metastably at low pressures in lunar basalts by the rapid cooling of magma (to below $990{ }^{\circ} \mathrm{C}$ at $2{ }^{\circ} \mathrm{C}$ per hour) at or near the surface were reported earlier, particularly in high-K basalts, olivine basalts, pigeonite basalts, ilmenite basalts, feldspathic basalts, and very high-Ti basalts in the Apollo 11, Apollo 12, Apollo 15, Apollo 17, and Apollo 14 samples (Lindsley and Burnham 1970; Lindsley 1972; Papike et al. 1991).

The Mare Riccioli pyroxenes are mostly subcalcic-augites to augites while the Mare Grimaldi pyroxenes comprise pigeonite and augites (Fig. 10D). The chemical trend of these compositions is commonly the reflection of a combination of factors such as melt composition, crystallization history, and late-stage to subsolidus cooling rate (cf. Bence and Papike 1972; Papike et al. 1976). The augites from R1 and R2 show a compositional cluster near the Di-Hd join (Fig. 10D). This kind of clustering is common in pyroxenes of quickly cooled 
basalts. The subcalcic-augites from both these units show a clustering towards the forbidden zone. In the R1 and R2 units, the crystallization commences with primary Mg-rich augite compositions, representing the initial stage of crystallization of the magma. A sudden drop in the calcium content of augites is observed (Fig. 10D). This discontinuity in the trend has possibly resulted from the onset of crystallization of plagioclase that preferentially incorporated $\mathrm{CaO}$ into plagioclase and thereby depleted calcium content in the residual melt. The Fe-enriched late-stage reidual liquid might have crystallized iron-rich late-stage subcalcic-augites. The intermediate calcium content of these pyroxenes between pigeonite and augite suggests their crystallization metastably from an iron-rich residual melt that cooled rather quickly in the late-stage (e.g., Smith and Lindsley 1971). The extreme iron enrichment is also indicating a fairly fast cooling rate and thereby violated the 'forbidden region' of the pyroxene quadrilateral (Lindsley and Munoz 1969).

The compositions from G1, G2, G3, and G4 units exhibit a lower-Ca, and Fe-enrichment trend zoning to the metastable composition in the forbidden region along the Hd-Fs join (Fig. 10D). In the G1 unit, the Fe-rich subcalcic-augite compositions show tight clustering in the region of metastable pyroxenes in the quadrilateral. The extremely Fe-rich compositions in this unit might be indicative of crystallization from a highly fractionated magma at a fast cooling rate. This compositional clustering might also be the result of the mantling of the olivine by pyroxenes that hindered the former from reacting with the liquid. However, this scenario is beyond the scope of this study. Further, the G2 and G3 units are showing distinct chemical trends starting with the crystallization of Fe-rich pigeonite followed by subcalcic-augite (Fig. 10D). Although, few compositions from G2 and G3 units are seen to have crystallized at Mg-rich end of the quadrilateral. It is possible that crystallization in the G2 and G3 units started with primary $\mathrm{Mg}$-ich augites in early stages followed by the incoming of plagioclase and subsequent rapid crystallization of iron-rich subcalcic late-stage augites and pigeonites from the residual melt. This iron-enrichment with constant $\mathrm{Mg}$ at the expense of $\mathrm{Ca}$ is reflected in their occurrence as a metastable phase in the 'forbidden region' of the quadrilateral. The compositions in the G4 unit also show calcium content intermediate between pigeonite and augite, suggesting that they crystallized metastably from a quickly cooled late-stage melt (Fig. 10D). The compositional break in the augite trend due to preferential incorporation of $\mathrm{CaO}$ into plagioclase is not very common in fast cooled rocks as the plagioclase nucleation is very late or not at all in such rocks. However, the late residual melt in a slowly cooled magma might experience a latestage rapid cooling (quenching) and crystallize metastable pyroxene compositions which otherwise are not stable in the forbidden region of the quadrilateral. Therefore, the extremely Ferich pyroxenes in these basalts are possibly the result of the crystallization of a fractionated magma under the quenching conditions. The possibility of a subsolidus re-equilibration can also not be ruled out as augite-pigeonite exsolution is common in lunar basalts (Ross et al. 1970; Papike et al. 
1971; Takeda et al. 1975). However, the remote spectrochemical analysis limits the scope of detection of subsolidus exsolution in pyroxenes and, therefore, this is not understandable using this pyroxene thermometer (e.g., Lindsley and Anderson 1983).

Based on the observations, it can be inferred that the high-Ti basalts in the Mare Grimaldi crystallized from a Fe-enriched highly fractionated late-stage magma at a fast cooling rate $\left(\sim 2{ }^{\circ} \mathrm{C}\right.$ per hour) between $\sim 1100^{\circ} \mathrm{C}-1000^{\circ} \mathrm{C}$ (Fig. 10D). Whereas, the low-Ti basalts in the Mare Grimaldi crystallized from a rather $\mathrm{Mg}$ and $\mathrm{Ca}$-rich initial magma that underwent an ultralate stage rapid cooling at a rate between $1200^{\circ} \mathrm{C}-1000^{\circ} \mathrm{C}$. The chemical trend of low-Ti basalt in the Mare Riccioli conforms to a similar scenario where the cooling $\left(1200^{\circ} \mathrm{C}-1000^{\circ} \mathrm{C}\right)$ of an initial high $\mathrm{Ca}-\mathrm{Mg}$ magma followed a late-stage quenching through rapid crystallization. The intermediate-Ti basalts in the Mare Riccioli also suggest a quenching trend where an initial $\mathrm{Ca}$, and $\mathrm{Mg}$-rich magma experienced a late-stage fast cooling $\left(1100^{\circ} \mathrm{C}\right.$ $1000^{\circ} \mathrm{C}$ ) resulting in a metastable crystal-liquid equilibration.

\section{III.A.6. Model ages of Mare Grimaldi and Mare Riccioli using Crater-Size Frequency Distribution Technique (CSFD)}

The model ages for the basaltic units in the Mare Grimaldi and Mare Riccioli have been determined based on the CSFD technique. The Mare Grimaldi and Mare Riccioli basalts were previously dated by Hiesinger et al. 2010 and reported ages of $3.48 \mathrm{Ga}$ and $3.27 \mathrm{Ga}$, respectively. In the present study, the distinct basaltic units in the Mare Grimaldi and Mare Riccioli have been dated separately to understand the volcanic history of the basin (Fig. 11) (Table 1). The model age for the basaltic unit in G4 could not be determined based on the CSFD technique as the unit is more or less blanketed by ejecta from the Grimaldi B crater. The cumulative crater frequency plot of the $\mathrm{G} 1$ and $\mathrm{G} 2$ units revealed younger ages, $\sim 2.05 \mathrm{Ga} \pm 0.06$. Since both the units are showing similar ages, the crater counts of these areas have been merged, and the cumulative frequency plot along with the age isochron for these units are shown in a single plot displaying a common age of $2.05 \mathrm{Ga}$ (Fig. 11A \& C). The G3 unit in the Mare Grimaldi revealed a model age of $3.47 \mathrm{Ga}$ $\pm 0.08 / 0.19$ (Fig. 11C). The R1 unit the Mare Riccioli revealed an older age of $3.2 \mathrm{Ga}$ $\pm 0.2 / 0.6$ and a younger age of $1.5 \mathrm{Ga} \pm 0.07$ (Fig. 11B \& D). These older and younger model ages suggest at least two volcanic events in the R1 unit. As discussed earlier, few patches of intermediate-Ti, high-Fe basalts are seen within the R1 unit. The younger age of $1.5 \mathrm{Ga} \pm 0.07$ might be indicative of this late-stage intermediate-Ti magmatic event. It is speculated that the $3.2 \mathrm{Ga}$ volcanic event that occurred in the R1 unit is followed by a younger $1.5 \mathrm{Ga}$ event, identified as small patches of high-Ti basalts within the unit. The R2 unit revealed an age of $3.5 \mathrm{Ga} \pm 0.05 / 0.07(11 \mathrm{E})$. This older event of $3.5 \mathrm{Ga}$ in the $\mathrm{R} 2$ unit is coinciding with 
the age of low to intermediate-Ti basalts (G3) in the Mare Grimaldi. The age of the R1 unit in Mare Riccioli and G3 unit of Mare Grimaldi are consistent with the previous dates reported in the Hiesinger et al. 2010. In addition, new results show rather younger events of $1.5 \mathrm{Ga}$ in the Mare Riccioli and $\sim 2.05 \mathrm{Ga}$ in the intermediate to the high-Ti basaltic units of Mare Grimaldi. These relatively younger volcanic events in the Grimaldi basin has important implications for the thermal and volcanic history of the basin.

\section{DISCUSSIONS}

In the Mare Grimaldi, the low to intermediate-Ti basalts are widespread while the high-Ti olivine-bearing basalts are confined to the south-western part (Thesniya et al. 2020) (Fig. 4A-B and Fig. 6A \& C). The intermediate-Ti basalts in the Mare Riccioli also appear to have limited spatial extends which has been observed as small patches within the R1 unit (Fig. 4C-D). The spectrally visible high-Ti basaltic units are considered to be relatively younger materials based on their intrusive relationship with the surrounding low to intermediate-Ti basalts (Fig. 4). The model ages revealed that at least two major volcanic events spanning $~ 3.5 \mathrm{Ga}$ to $\sim 1.5 \mathrm{Ga}$ (Late ImbrianEratosthenian) have occurred in the Grimaldi basin (Fig. 11). The ages further emphasize that an older Late Imbrian volcanic event of $\sim 3.47 \mathrm{Ga}$ formed the low to intermediate-Ti basalts in the Mare Grimaldi, followed by the eruption of high-Ti magma at $\sim 2.5 \mathrm{Ga}$ ago (Eratosthenian period) (Fig. 11C). The Late Imbrian low to intermediate basalts in the G3 unit might have filled the entire low-lying region of the Mare Grimaldi and the Eratosthenian high-Ti basalts localized to the extents of G1 and G2 units. Also, the younger high and intermediate titanium basalts in the G1 and G2 units are seen intermixed with each other. This coalescing of high-Ti basalts in the G1 and G2 units with the intermediate-Ti basalts might be the result of impact-induced lateral mixing of high-Ti and underlying Late Imbrian low-Ti basalts (Giguere et al. 2000). The older event of $\sim 3.5 \mathrm{Ga}$ (Late Imbrian) in the Mare Riccioli is nearly coinciding with the formation age of the Late Imbrian ( 3.47) low to intermediate-Ti basalt in the Mare Grimaldi (Fig. 11D-E). This low-Ti magma erupted at $\sim 3.5 \mathrm{Ga}$ have filled the entire Riccioli unit whereas the low to intermediate-Ti basalts formed at $\sim 3.2 \mathrm{Ga}$ ago are spatially limited to the extent of the R1 unit (Fig. 11D). The youngest volcanic event occurred in the Mare Riccioli is at $\sim 1.5 \mathrm{Ga}$ ago (Eratosthenian period) which erupted intermediate- $\mathrm{Ti}$ basalts within the $\mathrm{R} 1$ unit. It is plausible that these Eratosthenian intermediate-Ti basalts formed in the Mare Riccioli (R1 unit) were the result of impact mixing of younger high-Ti basalts with the underlying Late Imbrian low-Ti basalts in the Mare Riccioli (Giguere et al. 2000). Furthermore, a correlation between ages and titanium contents of basalts has been observed (Table 1). The late-stage Eratosthenian basaltic units show intermediate to high titanium contents whereas the low to intermediate basalts were 
erupted during Late Imbrian Epoch. This progressive enrichment of $\mathrm{TiO}_{2}$ and $\mathrm{FeO}$ contents in the Mare Grimaldi and Mare Riccioli with time is consistent with the similar observations from other regions on the Moon, particularly mare basalts in Procellarum KREEP Terrane (PKT) and Mare Imbrium (e.g., Giguere et al. 2000; Bugiolacchi et al. 2008). The crystallization history of the pyroxenes from distinct basaltic units in the Mare Grimaldi and Mare Riccioli also revealed signs of multiple volcanic events in the Grimaldi basin. This observation is consistent with the emplacement of distinct basaltic units that erupted at different periods in the basin $(\sim 3.5 \mathrm{Ga}-$ $1.5 \mathrm{Ga}$ ). Based on the results from Hiesinger et al. 2010, it was believed that the volcanic activity occurred at $\sim 3.47 \mathrm{Ga}$ and 3.27 Ga ago and ceased soon after the eruption of Mare Riccioli. However, the results from the present study indicate that volcanism was active in the Grimaldi basin until $1.5 \mathrm{Ga}$ ago. The variations in the Ti-contents of mare basalts erupted over a long time span and its proportional correlation with time suggest lateral chemical heterogeneity of the lunar mantle (e.g., Morota et al. 2011). It is suggested that the high-Ti basalts in the Mare Grimaldi crystallized from a Fe-enriched highly fractionated late-stage magma at a fast cooling rate while the low-Ti basalts crystallized from a rather $\mathrm{Mg}$ and $\mathrm{Ca}$-rich initial magma that underwent an ultra-late stage rapid cooling under disequilibrium conditions. The possible source regions and emplacement mechanism of the basaltic magma that erupted in the Grimaldi basin during Late Imbrian and Eratosthenian period are discussed in the following section.

\section{IV.A. Possible origin and emplacement history of the Mare Grimaldi and the Mare Riccioli}

A schematic model of the evolutionary history of the Grimaldi basin based on evidence from the present study and incorporating the current understanding of the thermal evolution of the lunar interior is proposed. The stages in the evolution of the Grimaldi basin involving the eruption of mare basaltic units are marked by three major events (Fig. 12).

\section{Basin forming impact event (>3.9 Ga, Pre-Nectarian)}

The basin-forming impact event induces pressure release melting and produces secondary convection following the selenotherm uplift, which causes the melting of the lunar crust and upper mantle to a depth greater than the depth of the transient crater (Fig. 12A) (Elkins-Tanton et al. 2004). Grimaldi basin forming impact event would also have generated impact heat and might have triggered the melting of the lunar crust and upper mantle to a considerably greater depth below the impact point. The basaltic magma produced by this pressure release melting might have caused the eruption of older basalts through the fractures in the Grimaldi basin. However, the eruption of the older low-Ti basaltic units presently identifiable in the Mare Grimaldi and Mare Riccioli must not be related to the magma generated by pressure release melting, because the 
basin forming impact event occurred at $>3.9 \mathrm{Ga}$ ago, and the oldest visible basalts in the Grimaldi basin are $\sim 3.5 \mathrm{Ga}$ old. An age gap of approximately $700 \mathrm{Ma}$ can be observed between the time of formation of the Grimaldi basin and the low-Ti basalts in the Mare Grimaldi and Mare Riccioli. The impact generated magma would persist for $~ 350$ Ma following the impact-induced pressure release melting and associated secondary convection (Elkins-Tanton et al. 2004). If the older lowTi basaltic units in the Mare Grimaldi and Mare Riccioli are formed as a result of the eruption of an impact-generated magma, the magma would not have persisted for such a long period (Whitten et al. 2011). Therefore, it can be inferred that the surface mare basaltic units present in the Mare Grimaldi and Mare Riccioli are not related to the impact-induced decompression melting and subsequent magma generation.

Given the above inferences, different models already proposed by previous workers for the source regions and evolution of the mare basalts on the Moon have been assessed here to understand the origin and emplacement history of the mare basaltic units in the Mare Grimaldi and Mare Riccioli. The magma ocean cumulate model suggests the remelting of MagmaOcean cumulates, caused by the influx of a hot, deep $(\sim 1000 \mathrm{~km})$ magma that formed during its thermal evolution post-LMO, for the generation of mare basaltic magmas in the lunar upper mantle (Taylor and Jakes 1974; Solomon and Longhi 1977). In another model by Wieczorek and Phillips (2000), the presence of higher KREEP levels causes the initiation of partial melting in lunar mantle directly beneath the KREEP basalt layer in the PKT and leads to the generation of mare basalts in the region. However, this model can be ruled out as the Mare Grimaldi and Mare Riccioli lie outside the boundary of the PKT, and they do not show any signatures of enhanced heat-producing elements. Further, the differences in crustal thickness would lead to the asymmetric spatial distribution of mare basalts on the nearside of the Moon (Solomon 1975; Head 1976; Head and Wilson 1992). Grimaldi basin is located on the boundary of the thicker farside and thinner nearside. Furthermore, crustal thickness estimates are $\sim 8 \mathrm{~km}$ in the region of Mare Grimaldi and $\sim 32 \mathrm{~km}$ in Mare Riccioli (Wieczorek et al. 2013, model 1) (Suppl Fig. 3). The observed differences in the crustal thickness between Mare Grimaldi and Mare Riccioli could have led to the non-uniform eruptions of basaltic magma at different periods in the basin. Another model explains that the instabilities in the lunar mantle, followed by large scale mantle overturn, affect the emplacement and evolution of mare basalts (Hess and Parmentier 1995). This model is independent of basin formation impact events. The mode of emplacement of Grimaldi basalts would rather support this model.

II. Emplacement of the older low to intermediate-Ti basalts during the first phase of volcanism in Late Imbrian Epoch $(3.5 \mathrm{Ga}-3.2 \mathrm{Ga})$ 
The petrological models suggest that a late-stage ilmenite-clinopyroxene rich layer (ilm-cpx) formed between the underlying olivine-orthopyroxene cumulate layer (ol-opx) and the primary floatation crust during the final stages of solidification of the Lunar Magma Ocean (e.g., Snyder et al. 1992; Shearer et al. 2006; Elardo et al. 2011). The ilm-cpx rich layer included a higher abundance of incompatible elements (radiogenic elements) owing to their formation in the later stages of the magma ocean crystallization, and has a relatively higher density than the underlying ol-opx cumulate layer. This gravitational instability in the early formed lunar mantle triggered a solid-state mantle overturn, causing the ilm-cpx cumulate layer to diapirically sunk to the bottom and correspondingly the ol-opx rich layer rose to the top of the mantle (Ringwood and Kesson, 1976; Hess and Parmentier, 1995; Shearer et al. 2006) (Fig. 12B). The mantle overturn occurred at around $4372 \pm 35 \mathrm{Ma}(\mathrm{Sm}-\mathrm{Nd}$ isochron age) during or soon after the solidification of the lunar magma ocean (Sio et al. 2020). As a result of the overturn, the descended ilm-cpx bearing cumulates formed a layer near the core-mantle boundary (e.g., Hess and Parmentier 1995; De Vries et al. 2010). It was suggested that small portions of the early ilm-cpx layer remained in the upper mantle in "pods" ( 5-20 km dimensions) while several workers argued of a dynamic mixing of the descending ilm-cpx cumulates with the rising low-Ti ol-opx cumulates (e.g., Hess and Parmentier 1995; Giguere et al. 2000; Elkins-Tanton et al. 2002; De Vries et al. 2010). Petrological models also suggest lateral compositional heterogeneity in the lunar upper mantle compositions (up to $500 \mathrm{~km}$ depth) as reflected by the variations in titanium contents of mare basalts (Longhi 1992). This hybrid source region where primordial LMO cumulates mixed during the mantle overturn was suggested to be the source regions of the basaltic magmas (e.g., Shearer et al. 2006).

It was suggested that zones of partial melt, remained in the lunar mantle after initial global melting or generated by radioactive heating, have driven the early mare volcanism spanning EarlyNectarian to Late Imbrian Epoch. The buoyancy, crustal thickness, and impact basin topography were the factors that influence the ascent and eruption of these mare basaltic magmas (Head and Wilson 1992). Due to this mantle heating, magma could be produced at depths up to $400 \mathrm{~km}$ (Taylor 1982), and the buoyancy drives it to rise diapirically through the ductile regions of the lunar mantle. The buoyantly rising magma would be trapped at the base of the crust due to the relatively lower density of the lunar crustal materials. Due to the buoyancy trap, the magma diapirs stall at depths below the crust, and subsequent accumulation of excess pressures in the diapirs leads to the propagation of dikes to the surface and eruption (Head and Wilson 1992). The emplacement of low to intermediate-Ti basalts has occurred both in the Mare Grimaldi and Mare Riccioli in the Late Imbrian Epoch. The low to intermediate-Ti magma erupted at 3.47 Ga ago in the Mare Grimaldi might have been derived from the dynamically mixed hybrid source region in the mantle through partial melting of early cumulate materials at depths between 200- 
$400 \mathrm{~km}$, which subsequently rose diapirically to the surface through dikes (Kesson 1975) (Fig. 12B). The emplacement of Mare Riccioli basalts must not be related to the Riccioli crater forming impact event as the crater is older than the Orientale basin $(3.8 \mathrm{Ga})$. Rather, the low to intermediate titanium magma erupted at $\sim 3.5 \mathrm{Ga}$ and $3.2 \mathrm{Ga}$ ago in the Mare Riccioli might also have been derived by a similar process where melting of early cumulate materials in the upper mantle caused the generation of magmas. The magma diapirs would have been stalled at the base of the crust, and the excess pressure build-up caused the fracturing of the overlying crust and dike propagation to the surface through which the magma extruded (Fig. 12B). The low-lying topography resulted from basin-forming impact event might have favored the ascent and eruption of magma through hydrostatic effects (Head and Wilson 1992).

III. Emplacement of the younger intermediate to high-Ti basalts in Eratosthenian period ( 2.05 Ga-1.05 Ga)

The high-Ti basalts $\left(\mathrm{TiO}_{2}>9\right.$ wt. \%) having relatively higher ilmenite $\left(\mathrm{FeTiO}_{3}\right)$ content are believed to be sourced from the ilm-cpx cumulates in the lunar mantle. This ilm-cpx cumulate source region could either be the ilm-cpx layer sank to theottom post overturn or the material concurrently mixed with early oli-opx cumulates in the upper mantle. Each of these scenarios has been explored further. Firstly, radiogenic elements that sank along with the ilm-cpx cumulates to the bottom of the mantle generated radiogenic heat near the core-mantle boundary, which caused the deep ilm-cpx-rich material to rise as a hot plume (Hess and Parmentier 1995; Zhang et al. 2013). Since the melting temperatures of plume materials (ilmcpx cumulate materials) are lower than the surrounding ol-opx cumulates (Delano 1990), the ascended hot plume would undergo decompression melting and generate high-Ti magma. Another scenario is that the early ilm-cpx rich cumulates that remained in the partially molten zone of the upper mantle post-overturn melted to form high titanium magmas. The hot plume rising from the deeper ilm-cpx cumulate layer and directly generating high-Ti magmas could be the most plausible scenario. The high-Ti magmas erupted in the Mare Grimaldi at 2.05 Ga ago could have been generated by such a hot plume risen from the deeper ilm-cpx layer near the coremantle boundary (Fig. 12C). The factors such as the abundance of heat-producing elements in the deeper ilm-cpx cumulate layer and the density differences from the overlying mantle control the timing of the rising plume (Hess and Parmentier 1995). The estimated timing of such a rising plume is $\sim 2 \mathrm{Ga}$ after the overturn of the mantle (Hess and Parmentier 1995), which is consistent with the timing of the younger $\sim 2.05 \mathrm{Ga}$ volcanic event in the Mare Grimaldi. Further, the rising melts have a relatively higher density $\left(\sim 3000 \mathrm{~kg} / \mathrm{m}^{3}\right)$ than that of the anorthositic crust $(\sim 2750$ $\mathrm{k} / \mathrm{m}^{3}$ ), which prevents the magma from making its way to the surface (Wieczorek et al. 2001). The 
rising magma was not buoyant to rise through the lunar crust due to these density differences. In the case of Mare Grimaldi, exposures of pure anorthosites were detected in the peak ring craters of the basin. Though basin forming impact event has excavated the primary anorthositic crust to considerably greater depths, the crustal thickness remains at $\sim 8 \mathrm{~km}$ in the Mare Grimaldi and $\sim 32$ $\mathrm{km}$ in the Mare Riccioli (Suppl Fig. 3). It requires melting at higher temperatures (1800-2000K) for the high-Ti magmas to escape this density contrast (Wieczorek et al. 2001). The heating induced by ascending hot plume from the core-mantle boundary might have resulted in higher temperatures for the magma, which would allow it to rise through the less dense anorthositic crust (Wilson and Head 1981; Wieczorek et al. 2001). On the other hand, the intermediateTi magma of the younger event of $\sim 1.5 \mathrm{Ga}$ occurred in the Mare Riccioli might have been originated from the hybrid source region in the upper mantle where segregated pods of ilmcpx cumulates remained in the upper mantle post-overturn remelted by heating from hot plume to form the intermediate-Ti magma (Fig. 12C).

\section{CONCLUSIONS}

The present study has investigated the spectral and chemical characteristics and ages of the mare basaltic units, Mare Grimaldi and Mare Riccioli in the Grimaldi basin on the near side of the Moon.

- Apart from the discoveries that match with the previous identification of mare basalts of older ages in the Grimaldi basin, the present study has identified distinct and younger basaltic units of higher $\mathrm{FeO}$ and $\mathrm{TiO}_{2}$ contents in the Mare Grimaldi and Mare Riccioli. The high-Ti basalts in both the mare units are stratigraphically overlain on the low to intermediate-Ti basalts.

- The higher olivine abundance associated with the high-Ti basalts in the Mare Grimaldi indicates the presence of olivine basalts in the region.

- The dating of these distinct basaltic units has revealed that the Grimaldi basin has experienced at least two phases of volcanic events spanning the Late ImbrianEratosthenian period. The first phase of low to intermediate-Ti basaltic volcanism occurred at $\sim 3.5 \mathrm{Ga}$ ago in both the units, followed by the eruption of low to intermediate-Ti basalts in the Mare Riccioli at $\sim 3.2 \mathrm{Ga}$ ago. The younger event of intermediate to high-Ti basaltic volcanism occurred at $\sim 2.05 \mathrm{Ga}$ and $\sim 1.5$ Ga ago in the Mare Grimaldi and Mare Riccioli respectively.

- The crystallization history of the pyroxenes from distinct basaltic units also supports the idea that multiple volcanic eruptions have occurred in the Grimaldi basin. The 
high-Ti basalts in the Mare Grimaldi crystallized from a Fe-enriched highly fractionated late-stage magma at a fast cooling rate while the low-Ti basalts crystallized from a rather $\mathrm{Mg}$ and $\mathrm{Ca}$-rich initial magma that underwent an ultralate stage quenching.

- The origin and emplacement of these basaltic units in the Grimaldi basin are predicted to be independent of basin forming impact event, because of the huge time gap ( 700 Ma) existing between the eruptions of Grimaldi basaltic units ( 3.5$1.5 \mathrm{Ga})$ and basin forming impact event $(>3.9 \mathrm{Ga})$. It has been inferred that the origin and emplacement of these basalts are related to the global thermal evolution of the Moon, rather than relying on the basin forming impact event.

- The Late Imbrian low to intermediate-Ti basalts in both the Mare Grimaldi and Mare Riccioli are derived from melting of early cumulate materials caused by radioactive heating, or molten zones remained in the mantle after initial global melting, in the hybrid source region of the post-overturn upper mantle, and erupted through dikes propagated to the surface. The Eratosthenian intermediate to high-Ti magma erupted in the Mare Grimaldi would have been formed through partial melting caused by a hot plume risen from the deeper clinopyroxene-ilmenite rich cumulates near the core-mantle boundary.

- The Mare Riccioli intermediate-Ti basalts ( $1.5 \mathrm{Ga}$ event) formed through a different process where the ilm-cpx cumulates that remained in the upper mantle after the mantle overturn remelted to generate high-Ti magmas.

- The new results from the present study suggest that volcanism had not ceased in the Grimaldi basin at $3.2 \mathrm{Ga}$, rather it was active until $1.5 \mathrm{Ga}$ for approximately $\sim 2$ billion years spanning Late Imbrian to Eratosthenian period.

\section{ACKNOWLEDGMENTS}

Indian Space Research Organization (ISRO) supported this work through the Chandrayaan-1 AO (Announcement of Opportunity) project (Grant No.: Department of Space, ISRO/SSPO/Ch-1/2016-17) to V.J.R.. J. Flahaut is supported by a LUE future leader grant, a CNRS Momentum fellowship, and CNES. We thank the Director, IIST, for the generous support and encouragement. We acknowledge the use of data from the Chandrayaan-1, the first lunar mission of the Indian Space Research Organization (ISRO), archived at the Indian Space Science Data Center (ISSDC). The authors would like to thank the $\mathrm{M}^{3}$ (Chandrayaan-1) and LROC 
(NASA) team for making the datasets available in the public domain. We thank the SELENE (KAGUYA) MI team and the SELENE Data Archive for providing the SELENE (KAGUYA) MI data. SELENE is a Japanese mission developed and operated by JAXA. We greatly appreciate the constructive comments and suggestions from Prof. Edward Cloutis (AE), and journal reviewers, which immensely helped to improve the quality of this manuscript. We are grateful to Dr. Satadru Bhattacharya (Space Applications Center, Ahmedabad, India) and Mr. Satya Kumar (National Geophysical Research Institute, Hyderabad, India) for their help and fruitful discussions at several stages of the manuscript preparation.

\section{REFERENCES}

Adams J. B. (1974) Visible and near-infrared diffuse reflectance spectra of pyroxenes as applied to remote sensing of solid objects in the solar system. Journal of Geophysical Research 79(32), 4829-4836.

Adams J. B. (1975) Interpretation of visible and near-infrared diffuse reflectance spectra of pyroxenes and other rock-forming minerals. Infrared and Raman Spectroscopy of Lunar and Terrestrial Minerals, 91-116.

Adams, J. B., and T. B. McCord (1970) Remote sensing of lunar surface mineralogy: Implications from visible and near infrared reflectivity of Apollo 11 samples. Geochim. Cosmochim. Acta 3, 1937-1945.

Archinal B. A., A’Hearn M. F., Bowell E., Conrad A., Consolmagno G. J., Courtin R., Fukushima T., Hestroffer D., Hilton J. L., and Krasinsky G. A. (2011) Report of the IAU working group on cartographic coordinates and rotational elements: 2009. Celestial Mechanics and Dynamical Astronomy 109(2), 101-135.

Arya A. S., Rajasekhar R. P., Thangjam G., Ajai, Kiran Kumar A. S. (2011) Detection of a potential site for future human habitability on the Moon using chandrayaan-1 data. Current Science 100, 524-529.

Barker M., Mazarico E., Neumann G., Zuber M., Haruyama J., and Smith D. (2016) A new lunar digital elevation model from the lunar orbiter laser altimeter and SELENE terrain camera. Icarus 273, 346-355.

Bence A. and Papike J. (1972) Pyroxenes as recorders of lunar basalt petrogenesis: Chemical trends due to crystal-liquid interaction. In Lunar and Planetary Science Conference Proceedings, 431. 
Besse S., Sunshine J. M., and Gaddis L. R. (2014) Volcanic glass signatures in spectroscopic survey of newly proposed lunar pyroclastic deposits. Journal of Geophysical Research: Planets, 119(2), 355-372.

Besse S., Sunshine J., Staid M., Boardman J., Pieters C., Guasqui P., Malaret E., McLaughlin S., Yokota Y., and Li J.-Y. (2013) A visible and near-infrared photometric correction for moon mineralogy mapper ( $\left.\mathrm{M}^{3}\right)$. Icarus 222(1), 229-242.

Bhandari N. (2005) Chandrayaan-1: science goals. Journal of Earth System Science 114(6), 701709.

Boardman J. W., Pieters C., Green R., Lundeen S., Varanasi P., Nettles J., Petro N., Isaacson P., Besse S., and Taylor L. (2011) Measuring moonlight: An overview of the spatial properties, lunar coverage, selenolocation, and related Level 1B products of the moon mineralogy mapper. Journal of Geophysical Research: Planets 116(E6).

Bratt S. R., Solomon S. C., and Head J. W. (1985) The evolution of impact basins: Cooling, subsidence, and thermal stress. Journal of Geophysical Research: Solid Earth 90(B14), 1241512433.

Bugiolacchi R., and Guest J. E. (2008) Compositional and temporal investigation of exposed lunar basalts in the Mare Imbrium region. Icarus, 197(1), 1-18.

Burns R., Vaughan D., Abu-Eid R., Witner M., and Morawski A. (1973) Spectral evidence for $\mathrm{Cr} 3+, \mathrm{Ti} 3+, \mathrm{Fe} 2+$ rather than $\mathrm{Cr} 2+$ and $\mathrm{Fe} 3+$ in lunar ferromagnesian silicates. In Lunar and Planetary Science Conference Proceedings, 983.

Burns R. G. (1970) Crystal field spectra and evidence of cation ordering in olivine minerals. American Mineralogist: Journal of Earth and Planetary Materials 55(9-10), 16081632.

Burns R. G. (1993) Mineralogical applications of crystal field theory. Cambridge University Press, 224.

Burns R. G., Huggins F. E., and Abu-Eid R. M. (1972) Polarized absorption spectra of single crystals of lunar pyroxenes and olivines. The Moon 4(1-2), 93-102.

Charlier B., Grove T. L., Namur O., and Holtz F. (2018) Crystallization of the lunar magma ocean and the primordial mantle-crust differentiation of the Moon. Geochimica et Cosmochimica Acta 234, 50-69.

Chauhan M., Bhattacharya S., Pathak S., and Chauhan P. (2018) Remote spectral-compositional analysis of basalt mineralogy at Hansteen-Billy, Moon. Meteoritics \& Planetary Science 53(12), 2583-2595.

Chauhan P., Kaur P., Srivastava N., Bhattacharya S., Kumar A., and Goswami J. (2012) Compositional and morphological analysis of high resolution remote sensing data over central 
peak of Tycho crater on the Moon: implications for understanding lunar interior. Current Science 102(7), 1041-1046.

Cheek L., Pieters C., Boardman J., Clark R., Combe J., Head J., Isaacson P., McCord T., Moriarty D., and Nettles J. (2011) Goldschmidt crater and the Moon's north polar region: Results from the moon mineralogy mapper ( $\left.\mathrm{M}^{3}\right)$. Journal of Geophysical Research: Planets 116(E6).

Clark R. N., Pieters C. M., Green R. O., Boardman J., and Petro N. E. (2011) Thermal removal from near-infrared imaging spectroscopy data of the Moon. Journal of Geophysical Research: Planets 116(E6).

Clark R. N., and Roush T. L. (1984) Reflectance spectroscopy: Quantitative analysis techniques for remote sensing applications. Journal of Geophysical Research: Solid Earth, 89(B7), 63296340.

Cloutis E. A. and Gaffey M. J. (1991a) Pyroxene spectroscopy revisited: Spectral-compositional correlations and relationship to geothermometry. Journal of Geophysical Research: Planets 96(E5), 22809-22826.

Cloutis E. A. and Gaffey M. J. (1991b) Spectral-compositional variations in the constituent minerals of mafic and ultramafic assemblages and remote sensing implications. Earth, Moon, and Planets 53(1), 11-53.

Cloutis E. A., Gaffey M. J., Jackowski T. L., and Reed K. L. (1986) Calibrations of phase abundance, composition, and particle size distribution for olivine-orthopyroxene mixtures from reflectance spectra. Journal of Geophysical Research: Solid Earth 91(B11), 11641-11653.

Coombs C. R. (1989) Explosive volcanism on the Moon and the development of lunar sinuous rilles and their terrestrial analogs. Ph.D. Dissertation, Univ. of Hawaii, Honolulu, 241

Coombs C. R. and Hawke B. R. (1992) Pyroclastic deposits on the western limb of the Moon. In Lunar and Planetary Science Conference Proceedings, 303-312.

Delano J. W. (1990) Buoyancy-driven melt segregation in the earth's moon, I. Numerical results. In Lunar and Planetary Science Conference Proceedings, 3-12.

De Vries J., van den Berg A., and van Westrenen W. (2010) Formation and evolution of a lunar core from ilmenite-rich magma ocean cumulates. Earth and Planetary Science Letters 292(12), 139-147

Donaldson Hanna K., Cheek L., Pieters C., Mustard J., Greenhagen B., Thomas I., and Bowles N. (2014) Global assessment of pure crystalline plagioclase across the Moon and implications for the evolution of the primary crust. Journal of Geophysical Research: Planets 119(7), 15161545.

Elardo S. M., Draper D. S., and Shearer Jr C. K. (2011) Lunar magma ocean crystallization revisited: Bulk composition, early cumulate mineralogy, and the source regions of the highlands Mg-suite. Geochimica et Cosmochimica Acta 75(11), 3024-3045. 
Elkins-Tanton L. T., Hager B. H., and Grove T. L. (2004) Magmatic effects of the lunar late heavy bombardment. Earth and Planetary Science Letters 222(1), 17-27.

Freed A. M., Johnson B. C., Blair D. M., Melosh H., Neumann G. A., Phillips R. J., Solomon S. C., Wieczorek M. A., and Zuber M. T. (2014) The formation of lunar mascon basins from impact to contemporary form. Journal of Geophysical Research: Planets 119(11), 2378-2397.

Gaddis L. R., Staid M. I., Tyburczy J. A., Hawke B. R., and Petro N. E. (2003) Compositional analyses of lunar pyroclastic deposits. Icarus 161(2), 262-280.

Gaffey M. J., Bell J. F., Brown R. H., Burbine T. H., Piatek J. L., Reed K. L., and Chaky D. A. (1993) Mineralogical variations within the S-type asteroid class. Icarus 106(2), 573-602.

Gaffey M. J., Cloutis E. A., Kelley M. S., and Reed K. L. (2002) Mineralogy of asteroids. In Asteroids III, edited by Bottke W. F., Cellino A., Paolicchi P., and Binzel R. P. Tucson, Arizona, The University of Arizona Press, 183-204.

Giguere T. A., Taylor G. J., Hawke B. R., and Lucey P. G. (2000) The titanium contents of lunar mare basalts. Meteoritics \& Planetary Science 35(1), 193-200

Gopala Krishna B., Sanjay S., Srivastava P., and Kiran Kumar A. (2009) Digital elevation models of the lunar surface from chandrayaan-1 terrain mapping camera (TMC) Imagery-Initial results. In Lunar and Planetary Science Conference, 1694

Goswami J. (2010) An overview of the chandrayaan-1 mission. In Lunar and planetary science conference, 1591.

Goswami J. and Annadurai M. (2009) Chandrayaan-1: India's first planetary science mission to the Moon. Current Science, 486-491.

Green R., Pieters C., Mouroulis P., Eastwood M., Boardman J., Glavich T., Isaacson P., Annadurai M., Besse S., and Barr D. (2011) The moon mineralogy mapper ( $\left.\mathrm{M}^{3}\right)$ imaging spectrometer for lunar science: Instrument description, calibration, on-orbit measurements, science data calibration and on-orbit validation. Journal of Geophysical Research: Planets 116(E10).

Green R., Pieters C., Mouroulis P., Sellar G., Eastwood M., Geier S., Shea J., and Team M. (2008) Calibration, shipment and initial spacecraft integration of the moon mineralogy mapper $\left(\mathrm{M}^{3}\right)$ imaging spectrometer for the chandrayaan-1 mission. In Lunar and Planetary Science Conference, 1803.

Hartmann W. and Kuiper G. P. (1962) Concentric structures surrounding lunar basins. Communications of the Lunar and Planetary Laboratory 1, 51-66.

Haruyama J., Matsunaga T., Ohtake M., Morota T., Honda C., Yokota Y., Torii M., Ogawa Y., and Group L. W. (2008) Global lunar-surface mapping experiment using the lunar imager/spectrometer on SELENE. Earth, Planets and Space 60(4), 243-255. 
Hawke B., Coombs C., Gaddis L., Lucey P., and Owensby P. (1989) Remote sensing and geologic studies of localized dark mantle deposits on the Moon. In Lunar and Planetary Science Conference Proceedings, 255-268.

Hawke B., Giguere T., Gaddis L., Gustafson O., Lawrence S., Stopar J., Peterson C., Bell J., and Robinson M. (2012) Localized pyroclastic deposits in the Grimaldi region of the Moon. In Lunar and Planetary Science Conference, 1749.

Head III J. W. (1976) Lunar volcanism in space and time. Reviews of Geophysics 14(2), 265-300.

Head III J. W. and Wilson L. (1992) Lunar mare volcanism: Stratigraphy, eruption conditions, and the evolution of secondary crusts. Geochimica et Cosmochimica Acta 56(6), 2155-2175.

Hess P. C. and Parmentier E. (1995) A model for the thermal and chemical evolution of the Moon's interior: Implications for the onset of mare volcanism. Earth and Planetary Science Letters 134(3-4), 501-514.

Hiesinger H., Head III J., Wolf U., Jaumann R., and Neukum G. (2010) Ages and stratigraphy of lunar mare basalts in Mare Frigoris and other nearside maria based on crater size-frequency distribution measurements. Journal of Geophysical Research: Planets 115(E3).

Hiesinger H., Jaumann R., Neukum G., and Head III J. W. (2000) Ages of mare basalts on the lunar nearside. Journal of Geophysical Research: Planets 105(E12), 29239-29275.

Isaacson P. J., Petro N. E., Pieters C. M., Besse S., Boardman J. W., Clark R. N., Green R. O., Lundeen S., Malaret E., and McLaughlin S. (2013) Development, importance, and effect of a ground truth correction for the moon mineralogy mapper reflectance data set. Journal of Geophysical Research: Planets 118(3), 369-381.

Isaacson P. J., Pieters C. M., Besse S., Clark R. N., Head J. W., Klima R. L., Mustard J. F., Petro N. E., Staid M. I., and Sunshine J. M. (2011) Remote compositional analysis of lunar olivinerich lithologies with moon mineralogy mapper $\left(\mathrm{M}^{3}\right)$ spectra. Journal of Geophysical Research: Planets 116(E6).

Kaur P., Bhattacharya S., Chauhan P., and Kumar A. K. (2013) Mineralogy of mare serenitatis on the near side of the Moon based on chandrayaan-1 moon mineralogy mapper $\left(\mathrm{M}^{3}\right)$ observations. Icarus 222(1), 137-148.

Kesson S. (1975) Mare basalts-melting experiments and petrogenetic interpretations. In Lunar and Planetary Science Conference Proceedings, 921-944.

King T. V. and Ridley W. I. (1987) Relation of the spectroscopic reflectance of olivine to mineral chemistry and some remote sensing implications. Journal of Geophysical Research: Solid Earth 92(B11), 11457-11469.

Klima R., Pieters C., and Team M. (2010) The Colorful Moon: Science discoveries from the moon mineralogy mapper on chandrayaan-1. In Annual Meeting of the Lunar Exploration Analysis Group, 33. 
Klima R. L., Pieters C. M., Boardman J. W., Green R. O., Head J. W., Isaacson P. J., Mustard J. F., Nettles J. W., Petro N. E., and Staid M. I. (2011) New insights into lunar petrology: Distribution and composition of prominent low-Ca pyroxene exposures as observed by the moon mineralogy mapper ( $\left.\mathrm{M}^{3}\right)$. Journal of Geophysical Research: Planets 116(E00G06).

Kumar A., Chowdhury A. R., Banerjee A., Dave A., Sharma B., Shah K., Murali K., Joshi S., Sarkar S., and Patel V. (2009) Terrain mapping camera: A stereoscopic high-resolution instrument on chandrayaan-1. Current Science 96(4), 492-495.

Kumar A. K. and Chowdhury A. R. (2005) Terrain mapping camera for chandrayaan-1. Journal of Earth System Science 114(6), 717-720.

Lemelin M., Lucey P., Gaddis L., Hare T., and Ohtake M. (2016) Global map products from the Kaguya multiband imager at 512 ppd: Minerals, FeO, and OMAT. In Lunar and Planetary Science Conference, 2994.

Lindsley D. H. and Andersen D. J. (1983) A two-pyroxene thermometer. Journal of Geophysical Research: Solid Earth 88(S02), A887-A906.

Lindsley D. H. and Burnham C. W. (1970) Pyroxferroite: Stability and X-ray crystallography of synthetic Ca0. 15Fe0. 85SiO3 pyroxenoid. Science 168(3929), 364-367

Lindsley D. H. and Munoz J. L. (1969) Subsolidus relations along the join hedenbergiteferrosilite. American Journal of Science 267(Schairer Volume), 295-324.

Lindsley D. H., Papike J. J., and Bence A. E. (1972) Pyroxferroite: Breakdown at low pressure and high temperature. In Lunar and Planetary Science Conference 3, 483

Longhi J. (1992) Origin of picritic green glass magmas by polybaric fractional fusion. In Lunar and Planetary Science Conference Proceedings 22, 343-353

Longhi J., Walker D., Grove T., Stolper E. M., and Hays J. (1974) The petrology of the Apollo 17 mare basalts. In Lunar and Planetary Science Conference Proceedings, 447-469.

Lucey P. G., Blewett D. T., and Jolliff B. L. (2000) Lunar iron and titanium abundance algorithms based on final processing of Clementine ultraviolet-visible images. Journal of Geophysical Research: Planets, 105(E8), 20297-20305.

Lucey P. G., Blewett D. T., and Hawke B.R. (1998) Mapping the FeO and TiO2 content of the lunar surface with multispectral imagery. Journal of Geophysical Research: Planets, 103(E2), 3679-3699.

Lucey P. G., Taylor G. J., and Malaret E. (1995) Abundance and distribution of iron on the Moon. Science, 268(5214), 1150-1153.

Lucey S.-P., Gaddis L., Bell J., and Hawke B. (1984) Near-infrared spectral reflectance studies of localized lunar dark mantle deposits. In Lunar and Planetary Science Conference, 495-496.

Mazarico E., Rowlands D., Neumann G., Smith D., Torrence M., Lemoine F., and Zuber M. (2012) Orbit determination of the lunar reconnaissance orbiter. Journal of Geodesy 86(3), 193-207. 
McCauley J. F. (1973) Geologic map of the Grimaldi quadrangle of the Moon. scale 1:1,000,000, Map I-740, USGS, Department of the Interior, Washington, DC.

McEwen A. S., Robinson M. S., Eliason E. M., Lucey P. G., Duxbury T. C., and Spudis P. D. (1994) Clementine observations of the Aristarchus region of the Moon. Science 266(5192), 1858-1862.

Melosh H., Freed A. M., Johnson B. C., Blair D. M., Andrews-Hanna J. C., Neumann G. A., Phillips R. J., Smith D. E., Solomon S. C., and Wieczorek M. A. (2013) The origin of lunar mascon basins. Science 340(6140), 1552-1555.

Morota T., Haruyama J., Ohtake M., Matsunaga T., Honda C., Yokota Y., Kimura J., Ogawa Y., Hirata N., Demura H., and Iwasaki A. (2011) Timing and characteristics of the latest mare eruption on the Moon. Earth and Planetary Science Letters, 302(3-4), 255-266.

Muller P. M. and Sjogren W. L. (1968) Mascons: Lunar mass concentrations. Science 161(3842), 680-684.

Mustard J. F., Pieters C. M., Isaacson P. J., Head J. W., Besse S., Clark R. N., Klima R. L., Petro N. E., Staid M. I., and Sunshine J. M. (2011) Compositional diversity and geologic insights of the Aristarchus crater from moon mineralogy mapper data. Journal of Geophysical Research: Planets 116(E6).

Neukum G. (1983) Meteorite bombardment and dating of planetary surfaces. Habilitation Thesis for Faculty Membership, University of Munich, 186

Neukum G. and Ivanov B. (1994) Crater size distributions and impact probabilities on Earth from lunar, terrestrial-planet, and asteroid cratering data. Hazards due to Comets and Asteroids $\mathbf{1}$, $359-416$.

Neukum G., Ivanov B. A., and Hartmann W. K. (2001) Cratering records in the inner solar system in relation to the lunar reference system. In Chronology and Evolution of Mars, 55-86.

Neukum G., König B., Fechtig H., and Storzer D. (1975) Cratering in the Earth-Moon systemConsequences for age determination by crater counting. In Lunar and Planetary Science Conference Proceedings, 2597-2620.

Ohtake M., Matsunaga T., Haruyama J., Yokota Y., Morota T., Honda C., Ogawa Y., Torii M., Miyamoto H., and Arai T. (2009) The global distribution of pure anorthosite on the Moon. Nature 461(7261), 236.

Papike J., Taylor L., and Simon S. (1991) Lunar minerals. Lunar Sourcebook: A User's Guide to the Moon, 121-181.

Papike J. J., Bence A. E., Brown G. E., Prewitt C. T., and Wu C. H. (1971) Apollo 12 clinopyroxenes: Exsolution and epitaxy. Earth and Planetary Science Letters 10(3), 307-315

Papike J. J., Hodges F. N., Bence A. E., Cameron M., and Rhodes J. M. (1976) Mare basalts: crystal chemistry, mineralogy, and petrology. Reviews of Geophysics 14(4), 475-540 
Papike J. J. and Vaniman D. T. (1978) The lunar mare basalt suite. Geophysical Research Letters 5(6), 433-436

Peterson C., Hawke B., Lucey P., Coombs C., and Spudis P. (1995) Spectral reflectance studies of the Grimaldi region of the Moon. Geophysical Research Letters 22(22), 3055-3058.

Pieters C., Boardman J., Buratti B., Clark R., Green R., Head J., Lundeen S., Malaret E., McCord T., and Mustard J. (2007) $\mathrm{M}^{3}$ on chandrayaan-1: strategy for mineral assessment of the Moon. In Lunar and Planetary Science Conference, 1295.

Pieters C. M. (1998) Lunar materials from the visible to mid-infrared: The effects of space weathering. International Geology Review 40(11), 981-989.

Pieters C. M., Boardman J., Buratti B., Chatterjee A., Clark R., Glavich T., Green R., Head III J., Isaacson P., and Malaret E. (2009) The moon mineralogy mapper ( $\left.\mathrm{M}^{3}\right)$ on chandrayaan1. Current Science, 500-505.

Pieters C. M., Head J. W., Adams J. B., McCord T. B., Zisk S. H., and Whitford-Stark J. L. (1980) Late high-titanium basalts of the western maria: Geology of the flamsteed region of oceanus procellarum. Journal of Geophysical Research: Solid Earth 85(B7), 3913-3938.

Pieters, C. M., E. M. Fischer, O. Rode, and A. Basu (1993) Optical effects of space weathering: The role of the finest fraction. Journal of Geophysical Research 98, 20817-20824.

Pieters, C. M. et al.. (2000) Space weathering on airless bodies: Resolving a mystery with lunar samples. Meteoritics \& Planetary Science 35(5), 1101-1107.

Kesson S. E., and Ringwood A. E. (1976) Mare basalt petrogenesis in a dynamic moon. Earth and Planetary Science Letters 30(2), 155-163.

Robinson M., Brylow S., Tschimmel M., Humm D., Lawrence S., Thomas P., Denevi B., Bowman-Cisneros E., Zerr J., and Ravine M. (2010) Lunar reconnaissance orbiter camera (LROC) instrument overview. Space Science Reviews 150(1-4), 81-124.

Ross M., Bence A. E., Dwornik E. J., Clark J. R., and Papike J. J. (1970) Lunar clinopyroxenes: chemical composition, structural state, and texture. Science 167(3918), 628-630

Sato H., Robinson M. S., Lawrence S. J., Denevi B. W., Hapke B., Jolliff B. L., and Hiesinger H. (2017) Lunar mare $\mathrm{TiO}_{2}$ abundances estimated from UV/Vis reflectance. Icarus 296, 216-238.

Scholten F., Oberst J., Matz K. D., Roatsch T., Wählisch M., Speyerer E., and Robinson M. (2012) GLD100: The near-global lunar $100 \mathrm{~m}$ raster DTM from LROC WAC stereo image data. Journal of Geophysical Research: Planets 117(E12).

Scott D. H., McCauley J. F., and Mareta N. West (1977) Geologic map of the west side of the Moon. Reston, VA: US Geological Survey, Citeseer.

Shearer C. K., Hess P. C., Wieczorek M. A., Pritchard M. E., Parmentier E. M., Borg L. E., Longhi J., Elkins-Tanton L. T., Neal C. R., and Antonenko I. (2006) Thermal and magmatic evolution of the Moon. Reviews in Mineralogy and Geochemistry 60(1), 365-518. 
Sio C. K., Borg L. E., and Cassata W. S. (2020) The timing of lunar solidification and mantle overturn recorded in ferroan anorthosite 62237. Earth and Planetary Science Letters 538, 116219

Smith D. and Lindsley D. H. (1971) Stable and metastable augite crystallization trends in a single basalt flow. American Mineralogist: Journal of Earth and Planetary Materials 56(1-2), 225233

Smith D., Zuber M., Neumann G., Mazarico E., Head J., and Torrence M. (2011) Results from the lunar orbiter laser altimeter (LOLA): global, high resolution topographic mapping of the Moon. In Lunar and Planetary Science Conference, 2350.

Smith D. E., Zuber M. T., Jackson G. B., Cavanaugh J. F., Neumann G. A., Riris H., Sun X., Zellar R. S., Coltharp C., and Connelly J. (2010a) The lunar orbiter laser altimeter investigation on the lunar reconnaissance orbiter mission. Space Science Reviews 150(1-4), 209-241.

Smith D. E., Zuber M. T., Neumann G. A., Lemoine F. G., Mazarico E., Torrence M. H., McGarry J. F., Rowlands D. D., Head J. W., and Duxbury T. H. (2010b) Initial observations from the lunar orbiter laser altimeter (LOLA). Geophysical Research Letters 37(18).

Smith J., Anderson A., Newton R., Olsen E., Crewe A., Isaacson M., Johnson D., and Wyllie P. (1970) Petrologic history of the moon inferred from petrography, mineralogy and petrogenesis of Apollo 11 rocks. Geochimica et Cosmochimica Acta Supplement 1, 897.

Snyder G. A., Taylor L. A., and Neal C. R. (1992) A chemical model for generating the sources of mare basalts: Combined equilibrium and fractional crystallization of the lunar magmasphere. Geochimica et Cosmochimica Acta 56(10), 3809-3823

Solomon S. (1975) Mare volcanism and lunar crustal structure. In Lunar and Planetary Science Conference Proceedings, 1021-1042.

Solomon S. C., and Longhi J. (1977) Magma oceanography. I-Thermal evolution. In Lunar and Planetary Science Conference Proceedings 8, 583-599.

Solomon S. C. and Head J. W. (1979) Vertical movement in mare basins: Relation to mare emplacement, basin tectonics, and lunar thermal history. Journal of Geophysical Research: Solid Earth 84(B4), 1667-1682.

Solomon S. C. and Head J. W. (1980) Lunar mascon basins: Lava filling, tectonics, and evolution of the lithosphere. Reviews of Geophysics 18(1), 107-141.

Speyerer E., Robinson M., and Denevi B. (2011) Lunar reconnaissance orbiter camera global morphological map of the Moon. In Lunar and Planetary Science Conference, 2387.

Staid M. and Besse S. (2013) Spectral and stratigraphic mapping of lava flows in Mare Imbrium. In Lunar and Planetary Science Conference, 2661.

Staid M. I., Pieters C. M., Besse S., Boardman J., Dhingra D., Green R., Head J., Isaacson P., Klima R., and Kramer G. (2011) The mineralogy of late-stage lunar volcanism as observed 
by the moon mineralogy mapper on chandrayaan-1. Journal of Geophysical Research: Planets 116(E6).

Staid M. I. and Pieters C. M. (2000) Integrated spectral analysis of mare soils and craters: Applications to eastern nearside basalts. Icarus, 145(1), 122-139.

Stöffler D., Ryder G., Ivanov B. A., Artemieva N. A., Cintala M. J., and Grieve R. A. (2006) Cratering history and lunar chronology. Reviews in Mineralogy and Geochemistry, 60(1), 519-596.

Takeda H., Miyamoto M., Ishii T., and Lofgren G. E. (1975) Relative cooling rates of mare basalts at the Apollo 12 and 15 sites as estimated from pyroxene exsolution data. In Proceedings of the Sixth Lunar Science Conference Pergamon Press, 17-21.

Taylor S. R., and Jakes P. (1974) The geochemical evolution of the Moon. In Lunar and Planetary Science Conference Proceedings 5, 1287-1305.

Taylor S. R. (1982) Planetary science: A lunar perspective. Houston: Lunar and Planetary Institute, 3303.

Thesniya P. M., Rajesh V. J., and Flahaut J. (2020). High-titanium olivine-rich basalts from the Grimaldi basin on the nearside of the Moon: implications for the volcanic history of the basin. In Lunar and Planetary Science Conference, 2326, 3069.

Tooley C. R., Houghton M. B., Saylor R. S., Peddie C., Everett D. F., Baker C. L., and Safdie K. N. (2010) Lunar reconnaissance orbiter mission and spacecraft design. Space Science Reviews 150(1-4), 23-62.

Wagner R., Speyerer E., Robinson M., and Team L. (2015) New mosaicked data products from the LROC team. In Lunar and Planetary Science Conference, 1473.

Warren P. H. (1985) The magma ocean concept and lunar evolution. Annual Review of Earth and Planetary Sciences 13(1), 201-240.

Whitten J., Head J. W., Staid M., Pieters C. M., Mustard J., Clark R., and Taylor, L. (2011) Lunar mare deposits associated with the Orientale impact basin: New insights into mineralogy, history, mode of emplacement, and relation to Orientale basin evolution from moon mineralogy mapper (M3) data from chandrayaan-1. Journal of Geophysical Research: Planets 116(E6).

Wieczorek M. A., Neumann G. A., Nimmo F., Kiefer W. S., Taylor G. J., Melosh H. J., Phillips R. J., Solomon S. C., Andrews-Hanna J. C., and Asmar S. W. (2012) The crust of the Moon as seen by GRAIL. Science 339(6120), 671-675.

Wieczorek M. A. and Phillips R. J. (2000) The "Procellarum KREEP Terrane": Implications for mare volcanism and lunar evolution. Journal of Geophysical Research: Planets 105(E8), 20417-20430. 
Wieczorek M. A. and Zuber M. T. (2001) The composition and origin of the lunar crust: Constraints from central peaks and crustal thickness modeling. Geophysical Research Letters 28(21), 4023-4026

Wilhelms D. E., John F., and Trask N. J. (1987) The geologic history of the Moon. U.S. Geol. Surv. Spec. Pap 1348, 302

Wilson L. and Head III J. W. (1981) Ascent and eruption of basaltic magma on the Earth and Moon. Journal of Geophysical Research: Solid Earth 86(B4), 2971-3001.

Wöhler C., Lena R., Lazzarotti P., Phillips J., Wirths M., Pujic Z., and Group G.L.R.G. (2006) A combined spectrophotometric and morphometric study of the lunar mare dome fields near Cauchy, Arago, Hortensius, and Milichius. Icarus, 183(2), 237-264.

Wood J. (1975) Lunar petrogenesis in a well-stirred magma ocean. In Lunar and Planetary Science Conference Proceedings, 1087-1102.

Wood J. A. (1972) Thermal history and early magmatism in the Moon. Icarus 16(2), 229-240.

Wood J. A. (1983) The lunar magma ocean, thirteen years after Apollo 11. In Pristine Highlands Rocks and the Early History of the Moon, 87.

Wood C. A. 2004. Astonishing megadome, Lunar Photo of the Day. http://www.lpod.org/archive/LPOD-2004-09-26.htm.

Wood J. A., Dickey Jr J. S., Marvin U. B., and Powell B. (1970) Lunar anorthosites and a geophysical model of the moon. Geochimica et Cosmochimica Acta Supplement 1, 965.

Yue Z., Yang M., Jia M., Michael G., Di K., Gou S., and Liu J. (2020) Refined model age for Orientale Basin derived from zonal crater dating of its ejecta. Icarus, 113804.

Zhang N., Parmentier E. M., and Liang Y. (2013) A 3-D numerical study of the thermal evolution of the Moon after cumulate mantle overturn: The importance of rheology and core solidification. Journal of Geophysical Research: Planets 118(9), 1789-1804

Zhang F., Zhu M.-H., and Zou Y. (2016) Late-stage Imbrium volcanism on the Moon: Evidence for two source regions and implications for the thermal history of Mare Imbrium. Earth and Planetary Science Letters 445, 13-27.

Zhang F., Zou Y., Zheng Y., Fu X., and Zhu Y. (2014) Lunar mare basalts in the Aristarchus region: Implications for the stratigraphic sequence from Clementine UVVIS data. Icarus 227, 132-151.

Zhong Z., Yan J., Rodriguez J. A. P., and Dohm J. M. (2018) Ancient selenophysical structure of the Grimaldi basin: Constraints from GRAIL gravity and LOLA topography. Icarus 309, 411421. 


\section{FIGURE CAPTIONS}

Fig. 1. A) LROC-WAC mosaic (Speyerer et al. 2011) of the western limb of the Moon in stereographic projection, centered on the Grimaldi basin at $5^{\circ} \mathrm{S}, 68^{\circ} \mathrm{W}$. The white rectangle on the image outlines the area chosen for the present study. B) WAC grey-scale mosaic image of the Grimaldi basin. The inner ring and basin rim are outlined in white. C) Color-coded LRO-LOLA \& Kaguya Terrain Camera Merge DEM (Barker et al. 2016a) of the Grimaldi basin showing the major topographic units in the basin. The mare basaltic units, namely Mare Grimaldi and Mare Riccioli, have also been labeled in the figure.

Fig. 2. Simplified geomorphologic map of the Grimaldi basin. Major morphologic units in the basin are mapped.

Fig. 3. $\mathrm{M}^{3} \mathrm{R} 1578 \mathrm{~nm}$ albedo map of the (A) Mare Grimaldi and (B) Mare Riccioli (stretched from 0.057-0.184). The distinct basaltic units within the Mare Grimaldi (G1, G2, G3, G4) and Mare Riccioli (R1, R2) are delineated based on the albedo variations.

Fig. 4. A) Kaguya-MI derived the $\mathrm{FeO}$ abundance map of the Mare Grimaldi (Lemelin et al. 2016). B) LROC WAC derived $\mathrm{TiO}_{2}$ abundance map of the Mare Grimaldi (Sato et al. 2017). C) Kaguya-MI-derived $\mathrm{FeO}$ abundance map of the Mare Riccioli. D) LROC $\mathrm{WAC} \mathrm{TiO}_{2}$ abundance map of the Mare Riccioli. Distinct basaltic units within Mare Grimaldi and Mare Riccioli have been delineated based on the variations in the $\mathrm{FeO}$ and $\mathrm{TiO}_{2}$ abundances. The basaltic units defined based on the $\mathrm{FeO}$ and $\mathrm{TiO}_{2}$ abundances are consistent with the spectrally defined units in the $\mathrm{M}^{3} \mathrm{R} 1578$ albedo map.

Fig. 5. A) M3 color composite image (Red: stretched between 0.572-2.660, Green: stretched between 0.38-0.98, Blue stretched between 0.049-0.095) of the Mare Grimaldi showing the mineralogical variations among pre-defined basaltic units within the Mare Grimaldi. The solid and dashed white lines demarcate the boundaries of the distinct basaltic units in the Mare Grimaldi. B) M3 color composite of the Mare Riccioli. The white circles in the image represent the locations where the reflectance spectra have been extracted. The white polygons in the image represent the locations from where the soil spectra were obtained. (C-D) Clementine color ratio image of the Mare Grimaldi and Mare Riccioli showing the presence of basaltic units having compositional differences. The blue shades in the image represent the high-Ti basalts (McEwen et al. 1994; Pieters et al. 1998). The red regions represent the anorthositic highlands, and the yellow/orange shades correspond to intermediate/low $\mathrm{TiO} 2$ mare units. 
Fig. 6. Color-coded IBD1000 parameter map of the (A) Mare Grimaldi and (B) Mare Riccioli. The white-purple shaded areas in the central units of the Mare Grimaldi and Mare Riccioli shows higher abundance values in the IBD1000 map. The outer G4 unit shows lower abundance values. The solid black lines demarcate the boundaries of the units with distinct abundance values in the IBD1000 parameter map. C) Kaguya MI derived olivine abundance map (in wt\%) of the Mare Grimaldi. D) Kaguya MI-derived olivine abundance map of the Mare Riccioli (Lemelin et al. 2016). The central basaltic units in the Mare Grimaldi exhibits greater olivine abundance. The solid white line demarcates the boundary of the basaltic units defined based on their olivine abundance.

Fig. 7. A-D) Representative reflectance spectra of the basaltic units in the Mare Grimaldi. The average reflectance spectra of the soil from each basaltic unit have been plotted. A-B) Normal and continuum removed spectra for G1, G2, G3, and G4 units in the Mare Grimaldi. The spectrum from the highland soil has also been plotted along with the soil spectra to understand the differences in the spectral slope and pattern among the soil of mare and highlands. C-D) Normal and continuum removed spectra for the R1 and R2 units in Mare Riccioli. The spectrum of the pyroclastic deposit in the western region of the Mare Riccioli has also been plotted along with the soil spectra. The black dashed lines are drawn at $1000 \mathrm{~nm}$ and $2000 \mathrm{~nm}$. E-F) Representative reflectance spectra of pure anorthosite (PAN) and crystalline plagioclase obtained from the Grimaldi $S$ crater located along the inner ring of the Grimaldi basin. The spectra collected locations have been labeled in Fig. 5A-B.

Fig. 8. A-H) Normal and continuum removed reflectance spectra of the clinopyroxenes collected from G1 (A-B), G2 (C-D), G3 (E-F), and G4 (G-H) units of the Mare Grimaldi. The black dashed lines are drawn at $1000 \mathrm{~nm}$ and $2000 \mathrm{~nm}$. The spectra collected locations have been shown in Fig. $5 \mathrm{~A}$.

Fig. 9. A-D) Normal and continuum removed reflectance spectra of the clinopyroxenes collected from the R1 (A-B) and R2 (C-D) units in the Mare Riccioli. The black dashed lines are drawn at $1000 \mathrm{~nm}$ and $2000 \mathrm{~nm}$. The spectra collected locations have been shown in Fig. 5B.

Fig. 10. A) BAR vs. Band I center ratio plot of the compositions sampled from the Mare Grimaldi and Mare Riccioli (after Gaffey et al. 1993). B) BAR vs. Band I displacement plot of the compositions from Mare Grimaldi and Mare Riccioli. The Band I displacement of each composition has been determined from the BAR vs. Band I calibration function originally derived 
by Gaffey et al. 2002. The Band I center of pyroxenes have been corrected for the estimated displacement in the Band I center. C) Band II centers are plotted against the corrected Band I centers of the pyroxene bearng spectra from the Mare Grimaldi and Mare Riccioli. The data are plotted along with the reference data for orthopyroxenes and clinopyroxenes from Adams (1974), modified by Cloutis and Gaffey (1991a). The data of synthetic pyroxenes from Klima et al. (2011) are also plotted for comparison. D) Mole \% compositions of pyroxenes in Mare Grimaldi and Mare Riccioli projected onto the pyroxene quadrilateral along with the equilibrium pyroxene temperatures based on the graphical thermometer developed by Lindsley and Anderson (1983).

Fig. 11. Model ages of the Mare Grimaldi and Mare Riccioli basaltic units determined based on the CSFD technique. A) Kaguya TC image of the Mare Grimaldi showing the crater count areas for each basaltic unit, G1, G2, and G3. B) TMC image of the Mare Riccioli showing the crater count area for the R1 and R2 units. C) Cumulative frequency plots of the G1-G2 (merged) and G3 unit in the Mare Grimaldi along with isochron and error for the data points. The younger age of $2.05 \mathrm{Ga}$ corresponds to the age of the merged unit, i.e., G1 \& G2 (High-Ti basalts). The older age of $3.47 \mathrm{Ga}$ shows the age of the $\mathrm{G} 3$ unit (low to Intermediate- $\mathrm{TiO}_{2}$ basalts). D) Cumulative frequency plot of the R1 unit along with age isochron and error for each data point. E) Cumulative frequency plot of the R2 unit along with age isochron and error for each data point.

Fig. 12. Schematic representation showing the stages involving emplacement of mare basaltic units in the Grimaldi basin. A) The early stage of the Grimaldi basin consisting of a transient crater cavity in the pre-Nectarian period. The impact generated heat would have caused the rising of isotherms and triggered melting up to several kilometers depth, often exceeds the depth of the transient crater cavity. B) The upliftment of deep-seated lithologies onto the surface by isostatic rebound followed by the impact event. The eruption of the low to intermediate-Ti basalts from the early cumulates in the upper mantle during $~ 3.5$ Ga to $3.2 \mathrm{Ga}$ period, which filled the lowlying interior of the basin and forms the lower Mare Grimaldi and Mare Riccioli units. C) Younger events of intermediate to high-Ti magmas erupted at $\sim 2.05 \mathrm{Ga}$ and $\sim 1.5 \mathrm{Ga}$ ago in the Mare Grimaldi and Mare Riccioli, respectively. The high-Ti magma erupted in the Mare Grimaldi, possibly sourced from a hot plume, risen from ilmenite-clinopyroxene cumulate layer near the core-mantle boundary. In contrast, the youngest intermediate-Ti Riccioli basalt formed from the magma generated through partial melting of pods of early ilm-cpx cumulates remained in the upper mantle after mantle overturn. 
Table 1. Estimated band parameters (avg.) of the pyroxenes from G1, G2, G3, G4, R1, and R2 units along with the absolute model ages of these distinct units in the Mare Grimaldi and Mare Riccioli

\section{SUPPLEMENTARY FIGURES}

Suppl Fig. 1. Illustration of the $\mathrm{M}^{3}$ continuum removal procedure. The continuum slope is drawn between the tangent points on both sides of the absorption bands (see methods).

Suppl Fig. 2. Pyroxene quadrilateral plot showing the relative abundance of the endmember pyroxene compositions in the Mare Grimaldi and Mare Riccioli.

Suppl Fig. 3. A) LRO DIVINER-derived crustal thickness map of the Grimaldi basin. B) Crustal thickness profile across the basin (NW-SE).

\section{TABLE}

Table 1 Estimated band parameters of the pyroxenes, range of compositions of $\mathrm{FeO}$ and $\mathrm{TiO}_{2}$ and the absolute model ages of distinct basaltic units in the Mare Grimaldi and Mare Riccioli (Age classification is based on Stoffler et al. 2006).

\begin{tabular}{|c|c|c|c|c|c|c|c|}
\hline Basalt & inits & $\begin{array}{l}\text { Band I Center (nm) } \\
\text { (avg.) }\end{array}$ & $\begin{array}{c}\text { Band II Center (nm) } \\
\text { (avg.) }\end{array}$ & $\mathrm{FeO}(\mathrm{wt} \%)$ & $\mathrm{TiO}_{2}(\mathrm{wt} \%)$ & \multicolumn{2}{|c|}{ Age (Ga) } \\
\hline \multirow{4}{*}{$\begin{array}{l}\text { Mare } \\
\text { Grimaldi }\end{array}$} & G1 & 958 & 2142 & $>22.5$ & $>9$ & $2.05 \pm 0.10$ & \multirow{2}{*}{ Eratosthenian period } \\
\hline & G2 & 959 & 2148 & $20-22.5$ & $6-10$ & $2.05 \pm 0.06$ & \\
\hline & G3 & 963 & 2159 & $15-20$ & $4-9$ & $3.47 \pm 0.08 / 0.19$ & Late Imbrian Epoch \\
\hline & G4 & 959 & 2146 & $12.5-15$ & $2-5$ & & n.a. \\
\hline \multirow{3}{*}{$\begin{array}{c}\text { Mare } \\
\text { Riccioli }\end{array}$} & & & & & & $1.5 \pm 0.07$ & Eratosthenian perioc \\
\hline & R1 & 983 & 2136 & $20-22.5$ & $3-8$ & $3.2 \pm 0.2 / 0.6$ & \multirow{2}{*}{ Late Imbrian Epoch } \\
\hline & $\mathrm{R} 2$ & 969 & 2080 & $12.5-20$ & $2-5$ & $3.5 \pm 0.05 / 0.07$ & \\
\hline
\end{tabular}


a)

b)

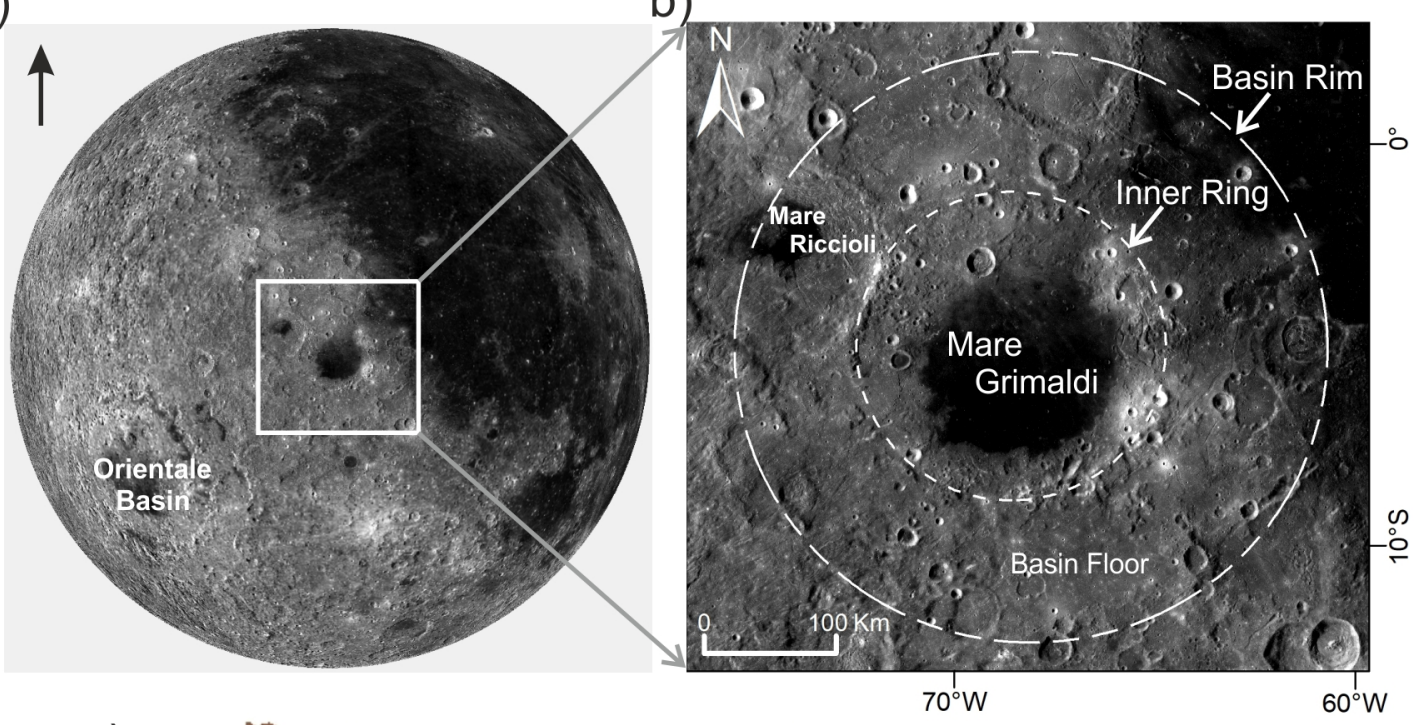

Highland Terrain

c)

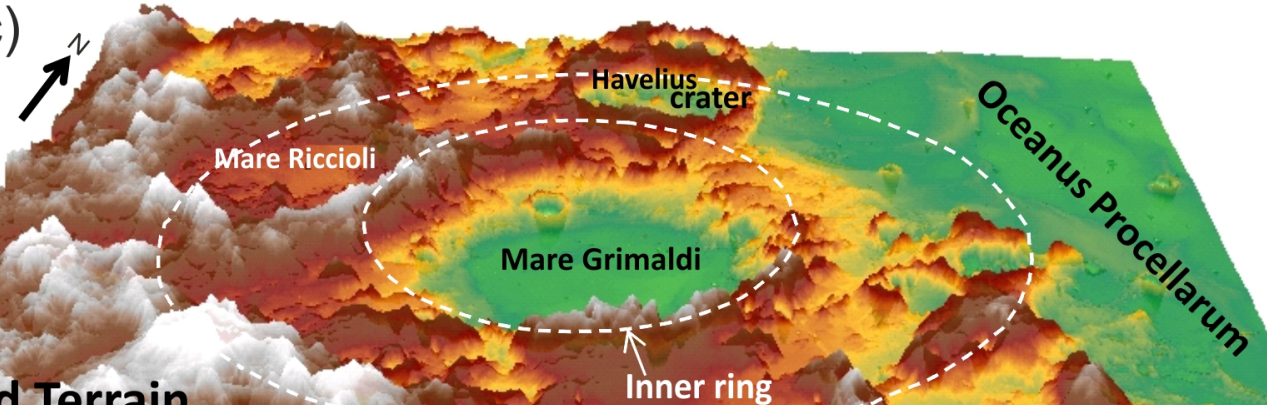




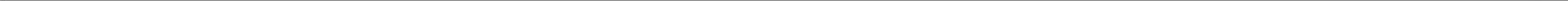



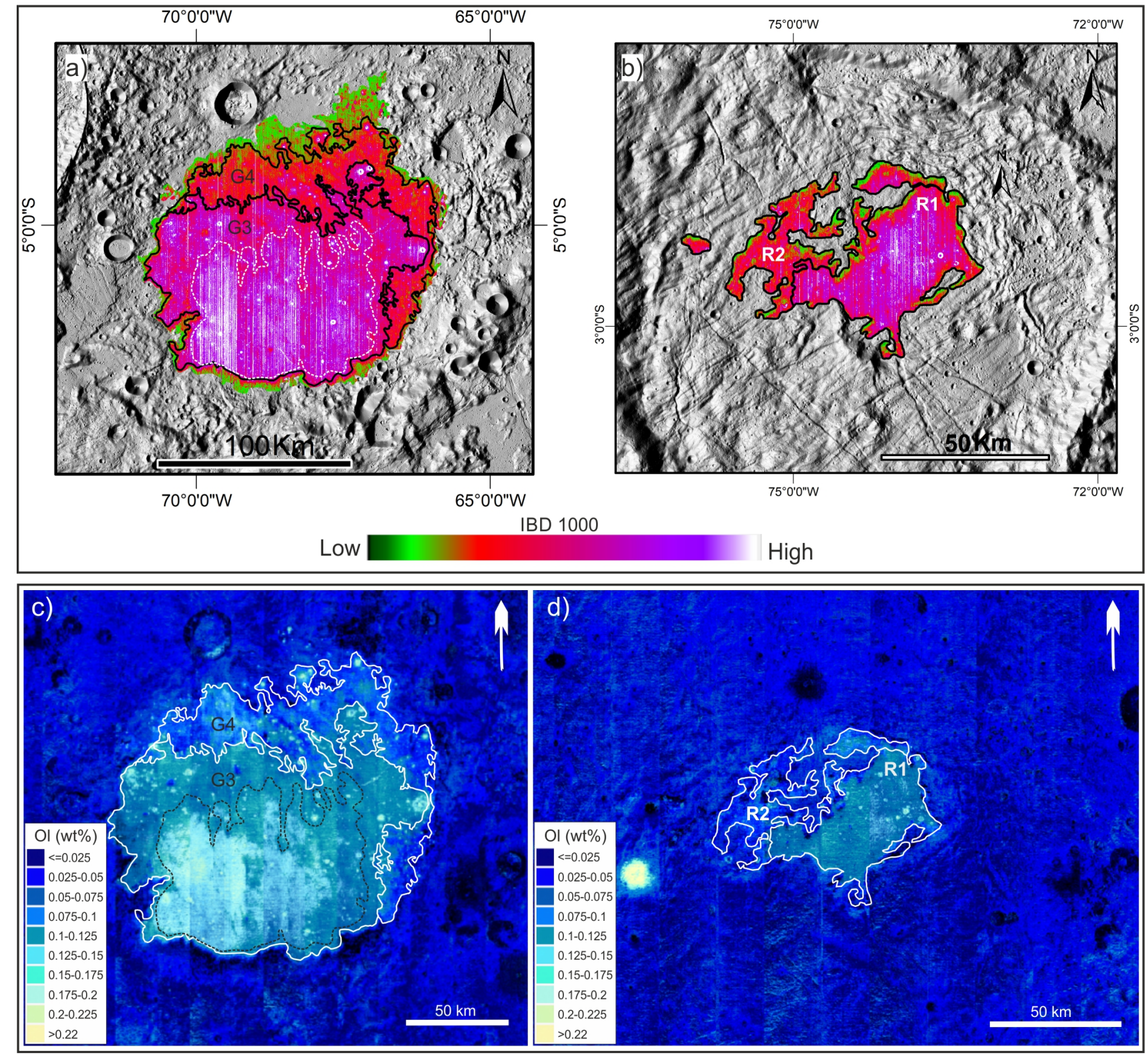

Fig. 6 

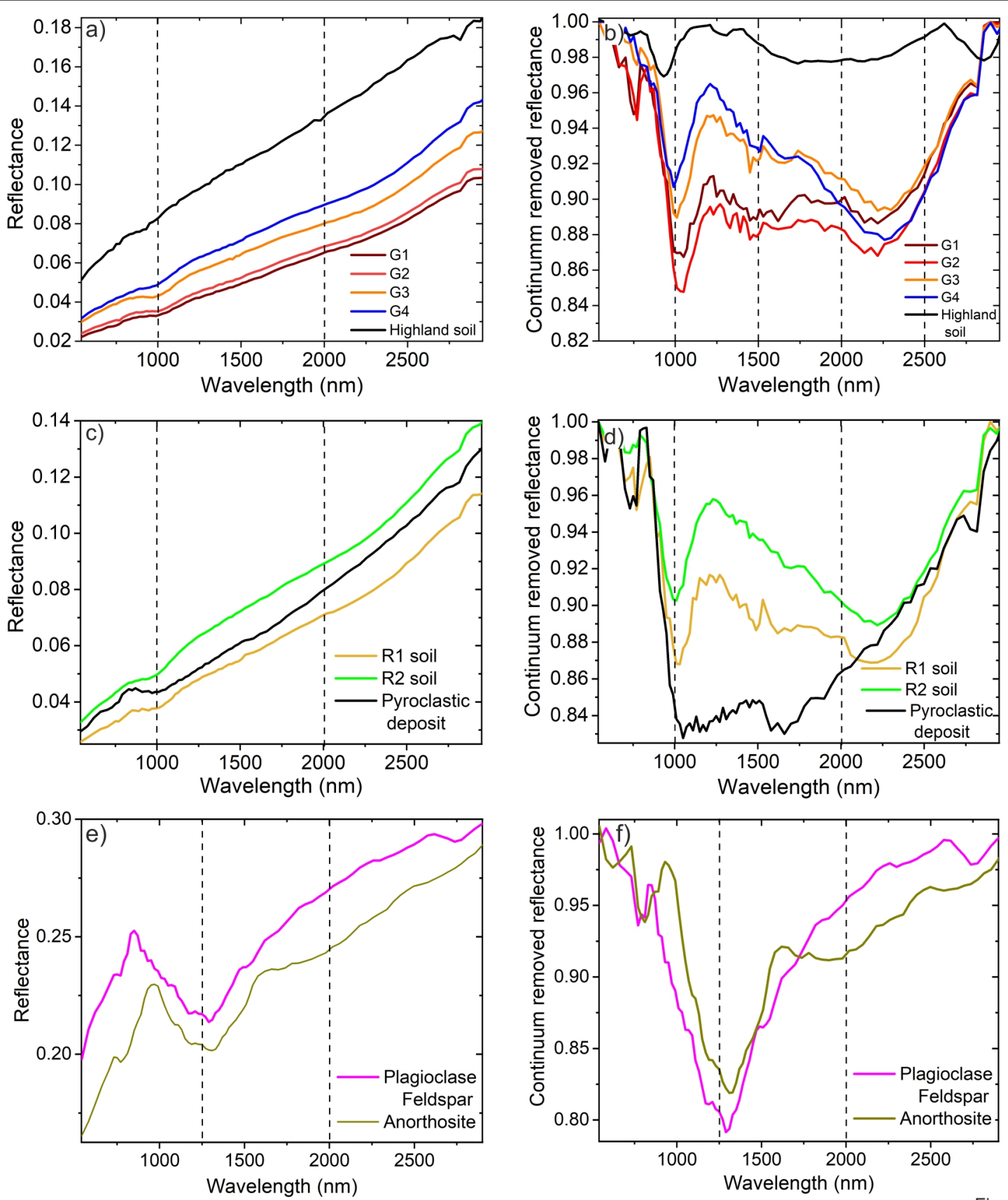

Fig. 7 

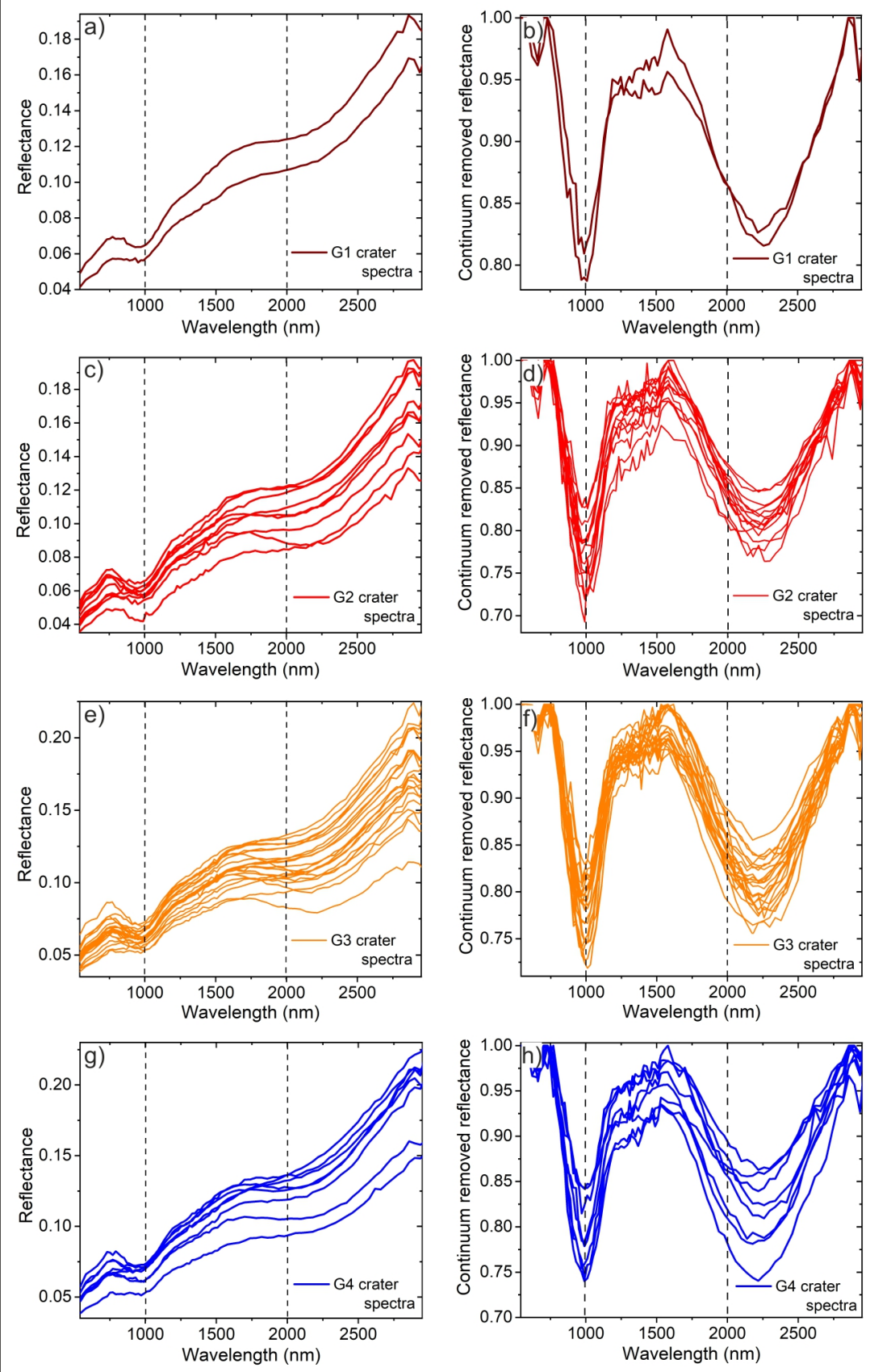

Fig. 8 

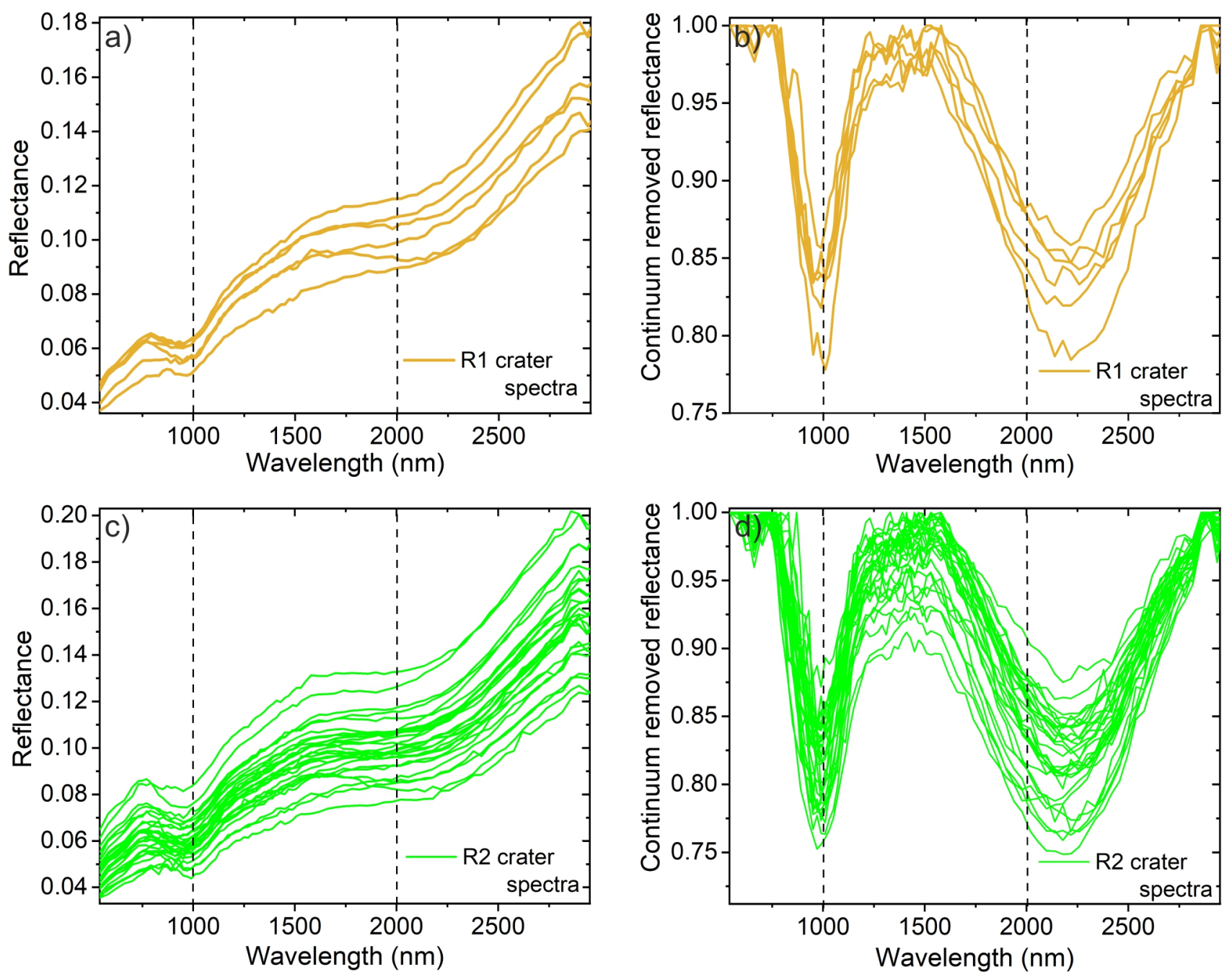

Fig. 9 

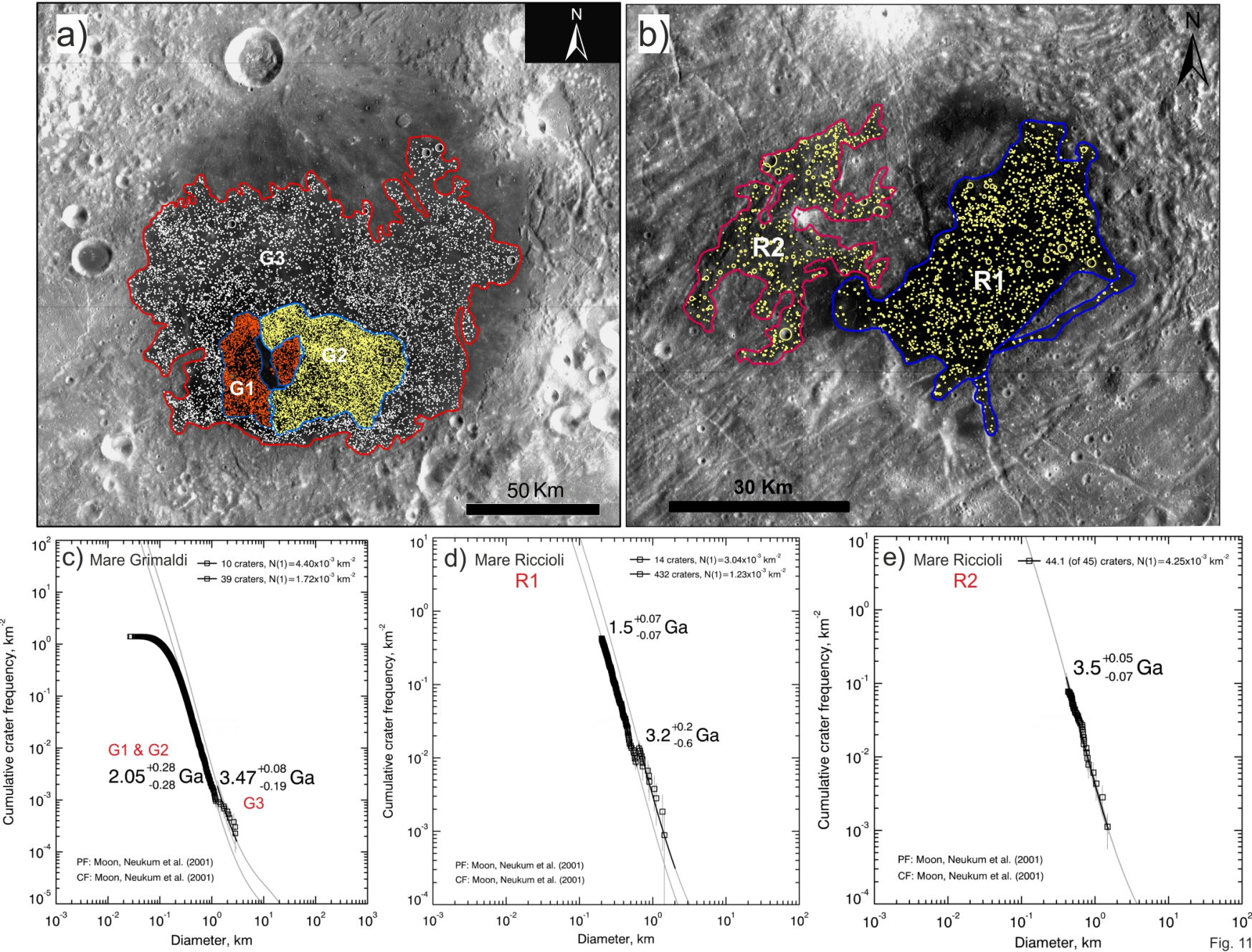
a)

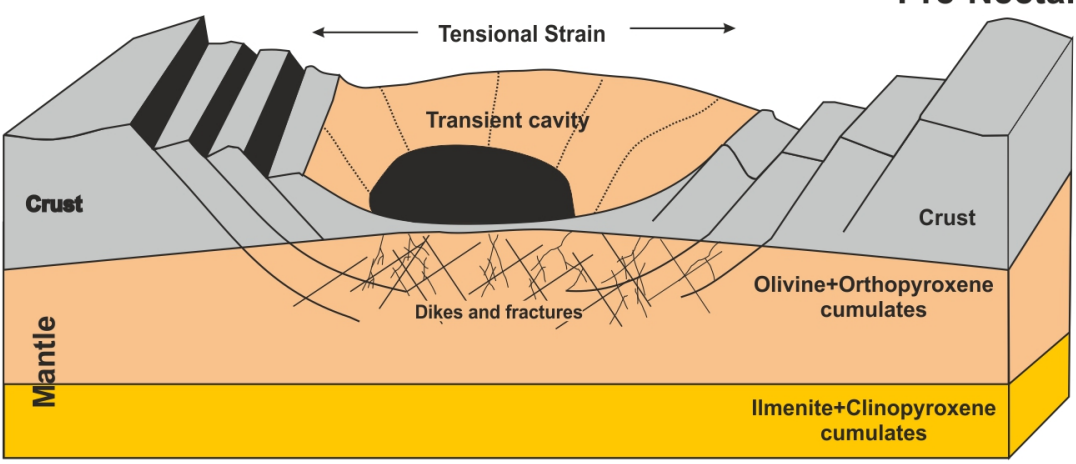

3.5 Ga-3.2 Ga

b)

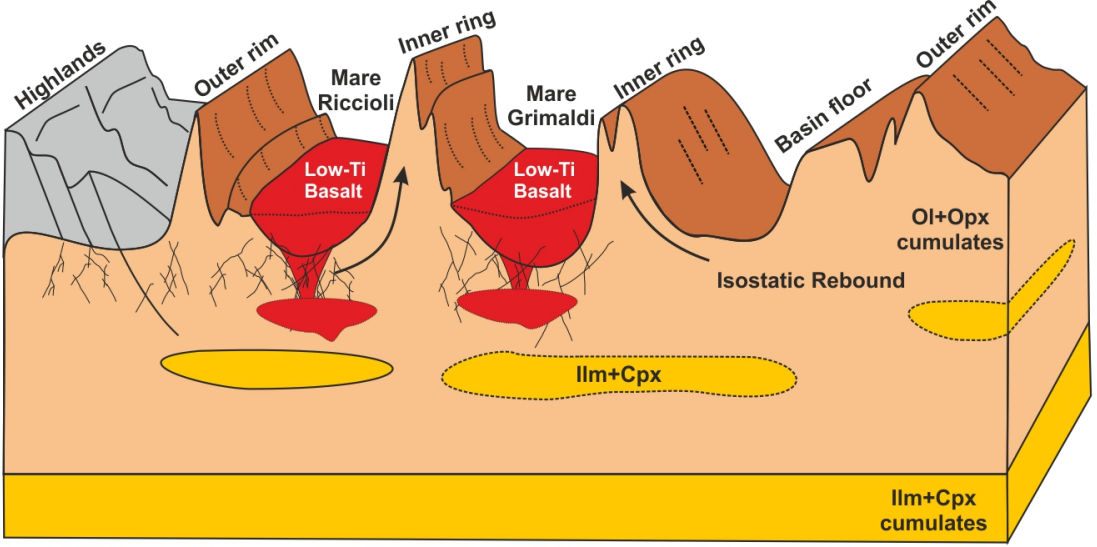

c)

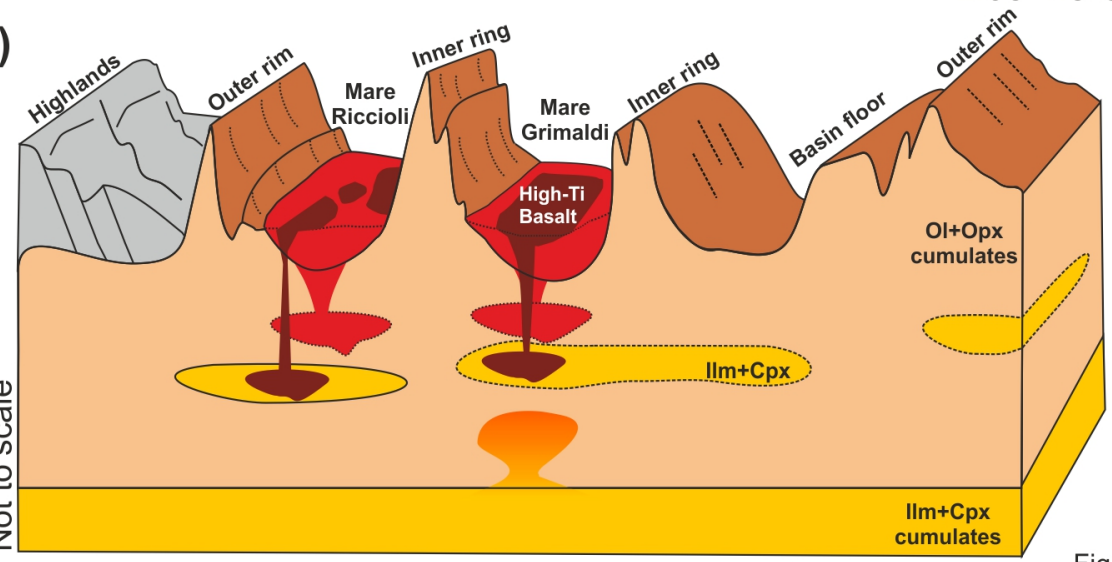

Fig. 12 


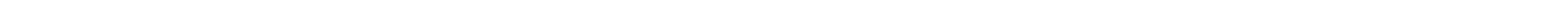




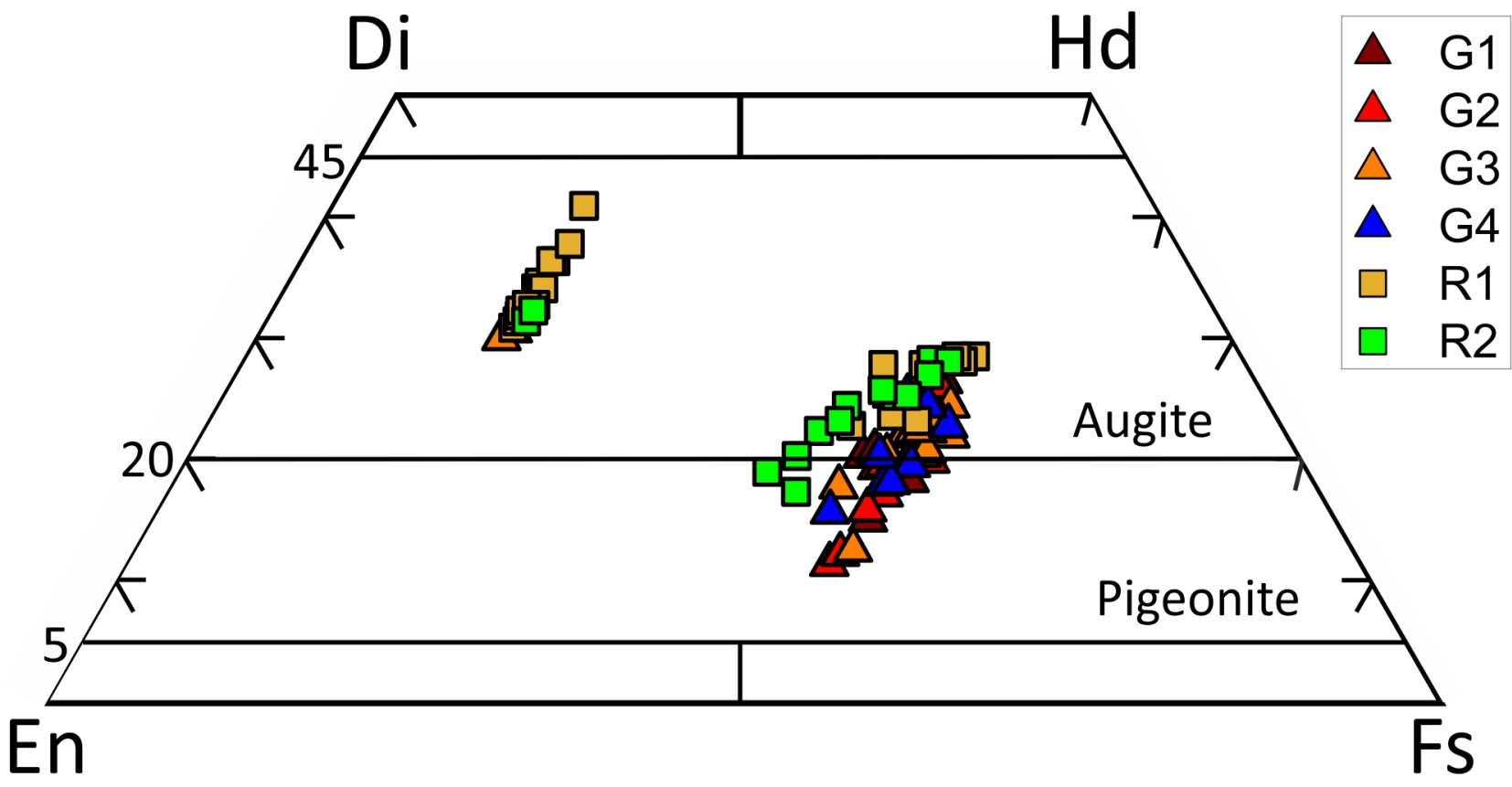

Suppl Fig. 2 
